Annales Geophysicae (2003) 21: 299-322 (C) European Geosciences Union 2003

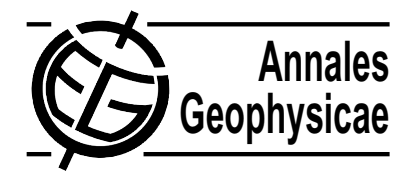

\title{
Seasonal variability in the Central Mediterranean Sea circulation
}

\author{
R. Sorgente ${ }^{1}$, A. F. Drago ${ }^{2}$, and A. Ribotti ${ }^{1}$ \\ ${ }^{1}$ CNR-IAMC, Sect. Oristano, c/o International Marine Centre, Loc. Sa Mardini, 09072 Torregrande-Oristano, Italy \\ ${ }^{2}$ Physical Oceanography Unit, IOI-MOC, University of Malta, c/o 36, Old Mint Str., Valletta VLT12, Malta
}

Received: 23 August 2001 - Revised: 4 June 2002 - Accepted: 20 June 2002

\begin{abstract}
A high resolution eddy-resolving primitive equation numerical model, based on the Princeton Ocean Model (POM), is used to study the seasonal variability of the general circulation in the Central Mediterranean Sea. The model is run on a seasonal cycle, perpetual year simulation for five years, with nesting to the coarser resolution Ocean General Circulation Model (OGCM), covering the whole Mediterranean Sea. The model results are compared to the current knowledge on the hydrography and dynamics of the area, with a special focus on the annual cycle of the Modified Atlantic Water (MAW), on the circulation in the Sardinia Channel, the water exchange across the Strait of Sicily, and on the transition and fate of the Levantine Intermediate Water (LIW). The results show that the adopted coupling techniques between the two models give a proficient downscaling of the large-scale OGCM flow field into the regional scale model. The numerical solution is also used to highlight the seasonal characteristics of important dynamical features in the area, as well as to shed light on the scarcely known circulation regimes along the north African shelf and slope.
\end{abstract}

Key words. Oceanography: general (numerical modelling); Oceanography: physical (currents; general circulation)

\section{Introduction}

The Central Mediterranean area, comprising the Sicilian Channel, is a large and dynamically active area connecting the eastern and the western Mediterranean sub-basins across the shallow sill at the Strait of Sicily (Fig. 1). The region is known to be characterized by a number of significant dynamical processes covering the full spectrum of temporal and spatial scales. Although it plays an important role in the water mass exchanges between the two basins, especially for the budget of the eastern Mediterranean basin, it has not received the same attention as the Strait of Gibraltar.

The general flow is mainly driven by the slow (vertical) Mediterranean thermohaline basin scale circulation (Hop-

Correspondence to: R. Sorgente (r.sorgente@imc-it.org) kins, 1978). This results in a two-layer flow through the Strait of Sicily with a fresh Modified Atlantic Water (MAW) eastward flow near the surface and a deeper salty Levantine Water outflow. Both flows are characterized by a significant seasonal and interannual variability. In the past, investigations have relied on hydrographic measurements, sub-surface current meter data and lagrangian drifting buoys, with an emphasis on the Strait area (Manzella, 1994; Grancini and Michelato, 1987; Poulain, 1998). Several authors have attempted to establish an estimate of the seasonal and interannual variability of the transports across the Strait mainly on the basis of two-layered models (Bethoux, 1980) or geostrophic flow calculations (Manzella et al., 1988; Moretti et al., 1993; Manzella, 1994; Astraldi et al., 1996). The results are, however, often incompatible and no clear situation emerges. The circulation is further influenced by strong mesoscale signals with periods from 3 to 10 days (Manzella et al., 1988). They are triggered mainly by intrinsic dynamics, by the interaction with the bottom topography and by the synoptic scale atmospheric forcing. With a Rossby radius of about $10 \mathrm{~km}$ in the shelf areas, these mesoscale phenomena cannot be detected and followed unless observations are available with sufficient detail in both time and space. $\mathrm{Nu}$ merical model simulations offer the solution to these deficiencies and constitute an important tool to study the phenomenology of the hydrodynamics in the area.

Modelling studies of the climatological seasonal structure of the circulation and water masses in the area have, however, addressed the problem only within the wider basin-scale applications (Malanotte-Rizzoli and Bergamasco, 1991; Pinardi and Navarra, 1993; Roussenov et al., 1995; Zavatarelli and Mellor, 1995; Wu and Haines, 1996; Horton et al., 1997a) and consequently, with a coarse spatial resolution. More specific model applications are the nowcast/forecast trials restricted to the southern and southeastern Sicilian coast, and based on dedicated cruises conducted in 1994, 1995 and 1996 (Robinson et al., 1999). Combined with an intensive data collection survey, a nonlinear primitive equation dynamical model in rigid-lid configuration (Lermusiaux, 1999) has been used to simulate the mesoscale 


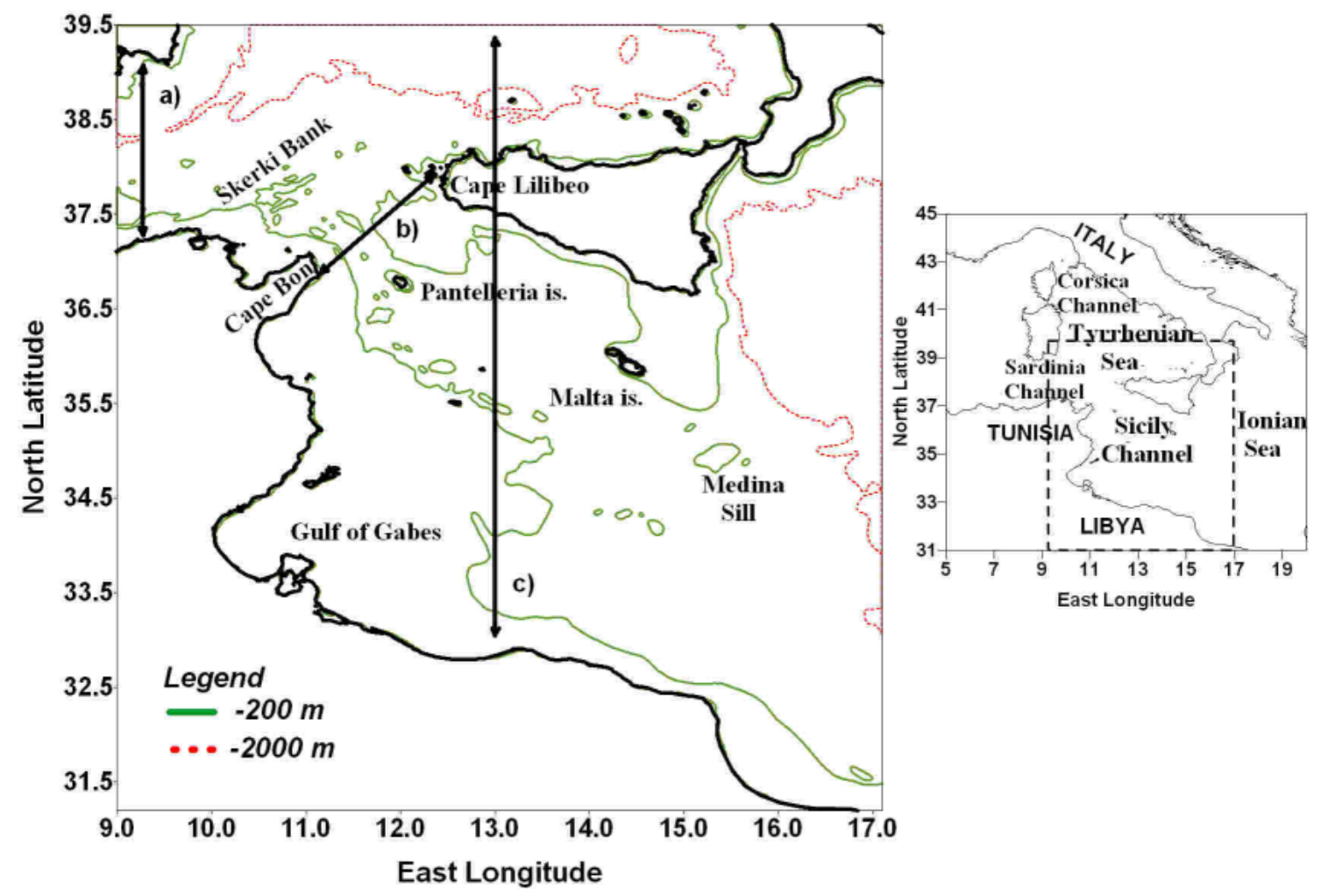

Fig. 1. Morphology of the Central Mediterranean Sea. Isolines indicate the $200 \mathrm{~m}$ and the $2000 \mathrm{~m}$ countours. a), b) and c) indicate the vertical sections at $9^{\circ} \mathrm{E}$, at the Sicily Strait and along longitude $13^{\circ} \mathrm{E}$.

fields and dominant variability in the Sicilian Channel during September 1996 (Lermusiaux and Robinson, 2001) at a horizontal resolution of $9 \mathrm{~km}$ and 20 levels in the vertical, using a topography-following (double sigma) transformation (Lozano et al., 1994; Sloam, 1996). Sorgente and Zavatarelli (2002) have applied a numerical simulation of the seasonal circulation in the Central Mediterranean area, based on the free surface Princeton Ocean Model (Blumberg and Mellor, 1987) and adopting the same approach used by Ezer and Mellor (1994) in diagnosing the north Atlantic circulation.

In this work we resort to a nested implementation of a three-dimensional primitive equation sigma-coordinate numerical model, permitting an improved grid resolution both horizontally and vertically, and producing an additional contribution to the present knowledge of the spatial and temporal variability of the circulation in the region.

Nesting is a finite difference modelling technique used to simulate a high resolution domain embedded in a lower resolution domain. It is a useful method to simulate the smallscale dynamics in a limited area, while allowing the large scales generated on the coarse grid to influence the nested grid. A substantial body of literature documenting nesting methods exists, particularly in numerical weather prediction (Koch and McQueen, 1987). For ocean flows, nesting has, however, only recently been implemented (Oey and Chen, 1992; Fox and Maskell, 1996; Oey, 1998) and has not yet been used to take full advantage of the more so- phisticated nesting techniques that have been developed in the atmospheric sciences. Within the modelling effort of the Mediterranean Forecasting System Pilot Project-MFSPP (Pinardi et al., 1999), a number of regional scale models have been coupled by one-way off-line nesting to the Ocean General Circulation Model (OGCM). The OGCM is based on the rigid-lid Modular Ocean Model (MOM), implemented in the Mediterranean basin at $1 / 8^{\circ}$ horizontal resolution, with 31 levels in the vertical (Demirov and Pinardi, 2003). It has been shown to be capable of reproducing the basin scale seasonal variability of the Mediterranean.

This work refers to the MFSPP regional model covering the Sicilian Channel, comprising the area of sea prior to the Strait of Sicily and extending towards the east, up to the longitude of $15^{\circ} \mathrm{E}$. The model is based on the free surface POM and is run on a seasonal cycle (perpetual year) simulation for five years. A one-way off-line nesting method (Zavatarelli et al., 2002) based on bilinear interpolation in the horizontal plane is adopted to downscale the large-scale OGCM flow field, with about $12.5 \mathrm{~km}$ of resolution, into the regional subbasin scale model with a resolution of about $5 \mathrm{~km}$. The coupling to the OGCM is necessary in order to transfer values of variables from the OGCM coarse grid to the finely spaced regional model grid at the location of the lateral boundaries. The utilization of the high resolution model has permitted a more detailed description of the circulation in the region including some mesoscale components that cannot be resolved 
by the coarse model. The model domain extension down to $31.2^{\circ} \mathrm{N}$ captures a large part of the Libyan continental shelf area and a firsthand valuable contribution to the knowledge of the circulation in this part of the Mediterranean can be derived within the limits imposed by the lack of data and consequently, the impoverished quality of the climatological fields in the area.

The paper is organized to give a short description of the characteristics of the general circulation in the area in Sect. 2, and an overview of the model characteristics, including the treatment of the boundary conditions and the nesting procedures in Sect. 3. An analysis of the main model results is made in the subsequent section with an emphasis on the seasonal variability. This includes a rigid-lid/free surface model-model assessment and an analysis of the simulated volume, heat and salt transport at the Strait of Sicily during the 5-year model integration. A summary and concluding remarks are made in the final section.

\section{Bathymetry, hydrology and general circulation}

The geometry of the Sicilian Channel has a great influence on the dynamics in the area. The fan-shaped configuration of the land boundaries has its narrowest constriction on the western extremity where the channel between Cape Bon (Tunisia) and Cape Lilibeo (Sicily) is only $143 \mathrm{~km}$ wide. The highly irregular bottom topography in the form of a submarine ridge further limits the flow (Fig. 2). This ridge is characterized by shallow banks along the Tunisian and Sicilian coast, and a central narrow passageway cutting along the NW-SE axis of the strait, forming part of an intermediate basin with an average depth of $500 \mathrm{~m}$. The African continental shelf is very wide and covers more than one-third of the aerial extent of the Strait. In the Gulf of Gabes, the bathymetry is shallower than $30 \mathrm{~m}$ for large stretches away from the coast. On the southern coast of Sicily, the shelf is bounded by two wide (approx. $100 \mathrm{~km}$ ) and shallow (100 m on average) banks on the western (Adventure Bank) and eastern extremities (Malta Channel area), while it narrows down considerably along its middle part. Along the eastern coast of Sicily and extending southward, there is the narrow Ionian shelf break which is very steep to the east of Malta (known as the Malta Escarpment). The shelf break fans out to the south and subsequently broadens to a gentle slope to the north of Libya.

The two-sill system at the Strait of Sicily constitutes the main exchange passageway for the Levantine Intermediate Water (LIW) between the eastern and western Mediterranean sub-basins. The first sill has a minimum depth of $365 \mathrm{~m}$ and oriented toward north-northwest; the second is deeper, reaching $430 \mathrm{~m}$ and oriented toward north (Frassetto, 1980). The major flux occurs through the narrower and deeper eastern passage close to the Sicilian shelf (Bethoux, 1980). The entrance of the LIW from the east occurs mainly at the Medina sill to the southeast of Malta.

The hydrological data portray a complex structure of the water masses in the region. From CTD and XCTD profiles

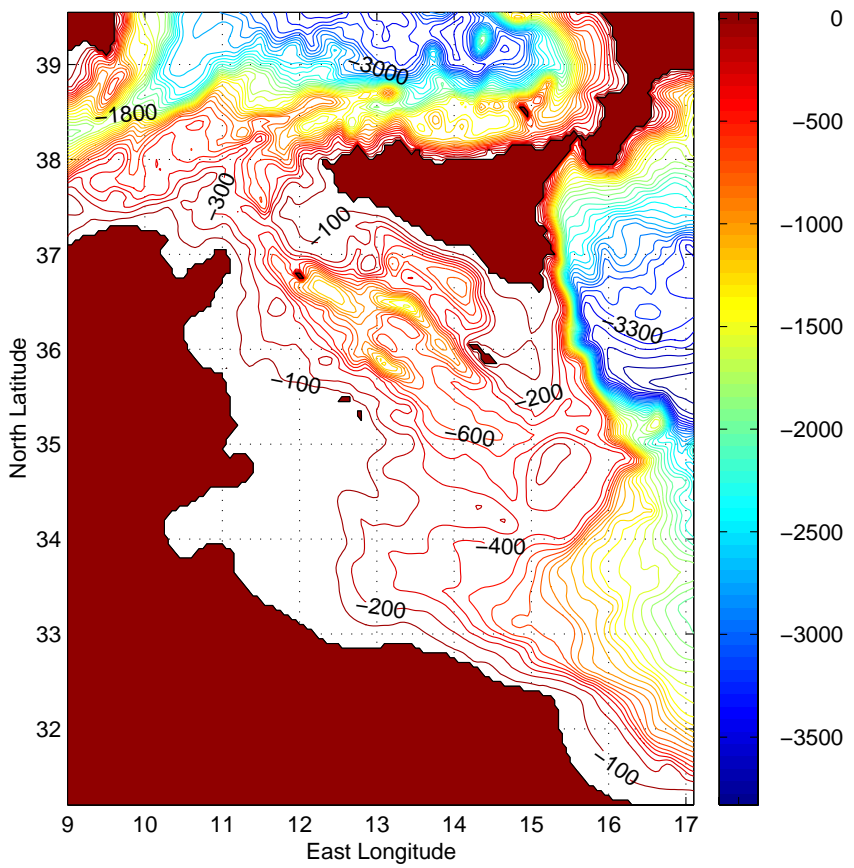

Fig. 2. The model bathymetry of the Central Mediterranean Sea based on the U.S. Navy bathymetric DBDB1 data set at a resolution of $(1 / 60)^{\circ}$. Depth is in meters and the contour interval is $100 \mathrm{~m}$.

taken during a cruise in November 1994, Robinson et al. (1996) have identified seven water masses in the northern area of the Sicily Channel and the northwest Ionian Sea, indicating the complexity of the processes in action. But to a first approximation the three main water masses in the strait are the upper layer Modified Atlantic Water, which enters into the Sicily Channel as an extension of the North African Algerian coastal current, the deeper Levantine Intermediate Water (LIW), and a transitional layer between these two water masses.

\subsection{The superficial water}

The Atlantic water enters the Mediterranean through the Strait of Gibraltar, becoming warmer and saltier along the African coast and constituting the origin of the MAW proceeding towards east (Warn-Varnas et al., 1999). In the Sardinia Channel the MAW is partially deviated northward by the shallow Tunisian Skerki Bank (Manzella, 1990) and then divides into three main branches under the effect of the bathymetry. One branch enters the Tyrrhenian Sea, flowing along the northern Sicilian coast; the other two MAW veins flow to the eastern Mediterranean basin crossing the Sicilian Channel (Astraldi et al., 1999). The main flow in the Strait is along the Tunisian coast, while the smaller flux on the southern Sicilian shelf gives rise to the northern meandering AIS-Atlantic Ionian Stream (Robinson et al., 1999). 
The seasonal variability of the two flows is significantly different. The southern flow along the African coast reaches its maximum in late fall (Astraldi et al., 1996). The MAW vein close to the southern Sicilian coast is most conspicuous during summer and autumn, proceeding eastward along the swift topographically controlled AIS. During winter, the MAW fills the whole extent of the Strait up to the westernmost tip of the southern Sicilian shelf. Starting from spring, this MAW then starts to progressively detach from the surface, taking the form of a subsurface core at a depth of about $60 \mathrm{~m}$ in autumn.

\subsection{The intermediate water}

The LIW is formed mainly in the northeastern Levantine basin during winter as a result of cooling and evaporation processes (Nittis and Lascaratos, 1998). After formation, the LIW spreads westward at an intermediate depth, penetrating over the Central Mediterranean ridge and eventually entering the western basin after crossing the Strait of Sicily. The LIW enters the Sicily Channel through the Medina sill with a salinity of about $38.74-38.75$ psu and a temperature of about $14.0-14.1{ }^{\circ} \mathrm{C}$ in autumn-winter (Warn-Varnas et al., 1999). It crosses the Strait of Sicily with its core at about $250 \mathrm{~m}$ and $270 \mathrm{~m}$ at each of the two sills. Then the whole LIW moves into the Tyrrhenian Sea, constrained by the topographic features and the Coriolis effect, and partially mixes with the upper and lower waters, becoming saltier (Sparnocchia et al., 1999). The flux of LIW is not constant but subject to a seasonal variability and calculated to be 2-3 times higher in winter $(3.2 \mathrm{~Sv})$ with respect to summer $(1.5 \mathrm{~Sv})$ (Manzella et al., 1988; Astraldi et al., 1996). Its core depth varies seasonally with the LIW being deeper in winter, below $200 \mathrm{~m}$, and closer to the surface in summer and autumn (Astraldi et al., 1999; Sparnocchia et al., 1999). In the Tyrrhenian Sea the LIW flows along the Italian coast, partially exiting northward from the Corsica Channel, especially during winter, and partially southwestward along the eastern Sardinian coast at a depth between 700-1000 m, then overlying the WMDWWestern Mediterranean Deep Water in the Sardinia Channel (Hopkins, 1978).

\section{Model setup}

\subsection{General}

The model used in this study is based on the Princeton Ocean Model (POM), a three-dimensional primitive equation, finite difference hydrodynamic model. The POM is a free surface, baroclinic, sigma-coordinate model that uses a time splitting technique to solve depth integrated and fully threedimensional equations with different time steps. It solves the equation of continuity (1), motion (2, 3 and 4$)$, conservation of temperature (5), salinity (6) and assumes hydrostaticity and the Boussinesq approximation. The equation of state (7) is an adaptation of the UNESCO equation of state revised by Mellor (1991).

The basic equations of the ocean model are written in orthogonal cartesian coordinates, with $x$ increasing eastward, $y$ increasing northward and $z$ increasing vertically upward, and synthetically described by the following equations:

$$
\begin{aligned}
& \frac{\partial u}{\partial x}+\frac{\partial v}{\partial y}+\frac{\partial w}{\partial z}=0 \\
& \frac{\partial u}{\partial t}+\left[u \frac{\partial u}{\partial x}+v \frac{\partial u}{\partial y}+w \frac{\partial u}{\partial z}\right]-f v=\frac{1}{\rho} \frac{\partial p}{\partial x}+\frac{\partial}{\partial z}\left(K_{M} \frac{\partial u}{\partial x}\right)+\frac{\partial}{\partial x}\left[2 A_{M} \frac{\partial u}{\partial x}\right]+\frac{\partial}{\partial y}\left[A_{M}\left(\frac{\partial u}{\partial y}+\frac{\partial v}{\partial x}\right)\right] \\
& \frac{\partial v}{\partial t}+\left[u \frac{\partial v}{\partial x}+v \frac{\partial v}{\partial y}+w \frac{\partial v}{\partial z}\right]+f u=\frac{1}{\rho} \frac{\partial p}{\partial y} \frac{\partial}{\partial z}\left(K_{M} \frac{\partial v}{\partial z}\right)+\frac{\partial}{\partial y}\left[2 A_{M} \frac{\partial v}{\partial y}\right]+\frac{\partial}{\partial x}\left[A_{M}\left(\frac{\partial u}{\partial y}+\frac{\partial v}{\partial x}\right)\right] \\
& \rho g=-\frac{\partial p}{\partial z} \\
& \frac{\partial \theta}{\partial t}+\left[u \frac{\partial \theta}{\partial x}+v \frac{\partial \theta}{\partial y}+w \frac{\partial \theta}{\partial z}\right]=\frac{\partial}{\partial z}\left(K_{H} \frac{\partial \theta}{\partial z}\right)+\frac{\partial}{\partial x}\left(A_{H} \frac{\partial \theta}{\partial x}\right)+\frac{\partial}{\partial y}\left(A_{H} \frac{\partial \theta}{\partial y}\right) \\
& \frac{\partial S}{\partial t}+\left[u \frac{\partial S}{\partial x}+v \frac{\partial S}{\partial y}+w \frac{\partial S}{\partial z}\right]=\frac{\partial}{\partial z}\left(K_{H} \frac{\partial S}{\partial z}\right)+\frac{\partial}{\partial x}\left(A_{H} \frac{\partial S}{\partial x}\right)+\frac{\partial}{\partial y}\left(A_{H} \frac{\partial S}{\partial y}\right) \\
& \rho=\rho(T, S, p)
\end{aligned}
$$

where $(u, v, w)$ are the velocity vector components, $\rho$ is the density, $g$ is the gravity constant, $p$ is the pressure and $f=2 \Omega \sin \varphi$ is the Coriolis parameter. The variables $\theta$ and $S$ are the potential temperature and salinity, respectively. The vertical mixing coefficients, $K_{M}$ and $K_{H}$, are calculated using the Mellor and Yamada (1982) turbulence closure scheme, while the horizontal diffusion terms $\left(A_{M}\right)$ are calculated using the Smagorinsky formula (Smagorinsky, 1993),

$$
A_{M}=C \Delta x \Delta y \sqrt{\left(\frac{\partial u}{\partial x}\right)^{2}+\frac{\left(\frac{\partial v}{\partial x}+\frac{\partial u}{\partial y}\right)^{2}}{2}+\left(\frac{\partial v}{\partial y}\right)^{2}},
$$


where $C$ is the coefficient of Smagorinsky diffusivity. This parameter is nondimensional and is known as the Horcon parameter (Mellor, 1998). In this application $C=0.1$.

The derivation of the sigma coordinate equations, from $(x, y, z, t)$ to $\left(x^{\star}, y^{\star}, \sigma, t^{\star}\right)$ coordinates where:

$x^{\star}=x, y^{\star}=y, \sigma=\frac{z-\eta}{H+\eta}, t^{\star}=t$,

can be found in Blumberg and Mellor (1987). In Eq. (9), $H(\mathrm{x}, \mathrm{y})$ is the bottom topography and $\eta(x, y, t)$ is the free surface elevation. The main advantage of the $\sigma$ system is that a smooth representation of bottom topography is obtained, and the use of the sigma coordinate system is a useful attribute in domains with significant variability in the topography, such as in the Central Mediterranean.

\subsection{The model domain}

It extends from $9.0^{\circ} \mathrm{E}$ to $17.1^{\circ} \mathrm{E}$ and from $31.2^{\circ} \mathrm{N}$ to $39.5^{\circ} \mathrm{N}$ (Fig. 2). The grid resolution is chosen to be $1 / 20^{\circ}$ for a better representation of the mesoscale eddy activity and of the exchanges through the Strait of Sicily. This resolution is below the first internal Rossby radius of deformation, about $10 \mathrm{~km}$ long (Send et al., 1999). The number of grid points used are 163 ( $x$-direction), 168 ( $y$-direction) and 22 sigma levels in the vertical. The sigma levels are bottom following, with logarithmic distribution near the surface. The external time step is set to $8 \mathrm{~s}$ with an internal integration every $240 \mathrm{~s}$.

\subsection{Bathymetry and initial condition}

The model bathymetry is based on the U.S. Navy bathymetric database DBDB1 with bilinear interpolation of depth data (mapped at $1 / 60^{\circ}$ ). Additional light smoothing is applied to reduce the sigma coordinate pressure gradient error (Mellor et al., 1994). The resulting topography is shown in Fig. 2. The maximum depth is about $4000 \mathrm{~m}$. The model was initialized with the temperature and salinity fields from the eightyear long OGCM perpetual year simulation (Demirov and Pinardi, 2003). It starts from the first of January with zero initial velocity.

\subsection{Lateral open boundary conditions}

The model has three open boundaries located in the southern Tyrrhenian Sea (along $39.5^{\circ} \mathrm{N}$ ), in the Sardinia Channel (along $9^{\circ} \mathrm{E}$ ) and in the open Ionian Sea (along $17.1^{\circ} \mathrm{E}$ ). At the lateral open boundaries the regional model receives information of temperature, salinity and velocity fields by one-way off-line nesting to the coarse resolution basin scale model in which it is embedded. The grid-nesting ratio between the two models is 2.5. The one-way nesting enables the transmission of information at the interconnecting boundaries from the coarse resolution grid to the fine resolution (nested) grid at each external time step, using a linear interpolation in time of 10-day averaged coarse model fields. On the vertical plane, the coarse and fine resolution models have different vertical coordinate systems. The coarse resolution model uses a $z$-level discretisation model, while the high resolution model uses a sigma-coordinate system. The main advantage with the latter vertical discretisation is that a smooth representation of the bottom topography can be obtained. In a recent study, Bell (1997) has shown that, especially with finer grids, the step structure of a $z$-level model can lead to vorticity errors and consequently, to errors in the barotropic component of the flow, leading to rather large temperature errors. In the sigma-coordinate system, the top numerical level $(k=1)$ follows the free sea surface, while the lowest numerical level $(k=k b)$ follows the bottom depth; for $1<k<k b$ the distance between the levels is fixed in proportion to each other, independent of elevation or depth.

At the open boundaries, the normal and tangential total velocity components are fully specified by a bilinear interpolation of the 10-day averaged coarse resolution model fields (MOM) onto the high resolution model grid (POM), then

$U_{\text {pom }}=U_{\text {mom }}$

with the exception of the eastern open boundary, where the following radiation condition is used:

$\frac{\partial U_{\mathrm{pom}}}{\partial t} \pm c_{e} \frac{\partial U_{\mathrm{pom}}}{\partial x}=0 ; c_{e}=\sqrt{g H}$

Since the coarse resolution model is a rigid-lid model, the barotropic normal velocities need to be adjusted to ensure conservation of volume. They are specified at each external time step by the following equation:

$\bar{U}_{\text {pom }}=\bar{U}_{\text {mom }} \frac{H}{H+\eta}$,

where $\bar{U}_{\text {pom }}$ is the vertically integrated velocity in the high resolution model, $\bar{U}_{\text {mom }}$ is the vertical integral of the velocity prescribed from the coarse model, and $\eta$ is the free surface elevation. The matching of the fields at the common boundaries between the two models must also ascertain that the mass transport at each respective open boundary is constrained to remain equal to that prescribed from the coarse model. This means that the total velocity component on the boundary of the high resolution grid needs to be adjusted so as to preserve the net transport across the boundary as specified on the coarse grid. Then,

$\int_{l_{1}}^{l_{2}} \int_{H_{\text {coarse }}}^{\eta} U_{\mathrm{pom}}^{\mathrm{tot}} d z d l=\int_{l_{1}}^{l_{2}} \int_{H_{\mathrm{high}}}^{\eta} U_{\mathrm{mom}}^{\mathrm{tot}} d z d l$.

The free surface elevation is not nested (zero gradient boundary condition). However, the free surface coarse resolution field enters indirectly through the specification of the boundary condition for the normal barotropic velocity component (Eq.12).

An upstream advection scheme is used for temperature and salinity:

$\frac{\partial(\theta, S)}{\partial t}+U \frac{\partial(\theta, S)}{\partial x}=0$.

In the case of outflow through the open boundaries, temperature and salinity are prescribed from the coarse resolution 
(a)

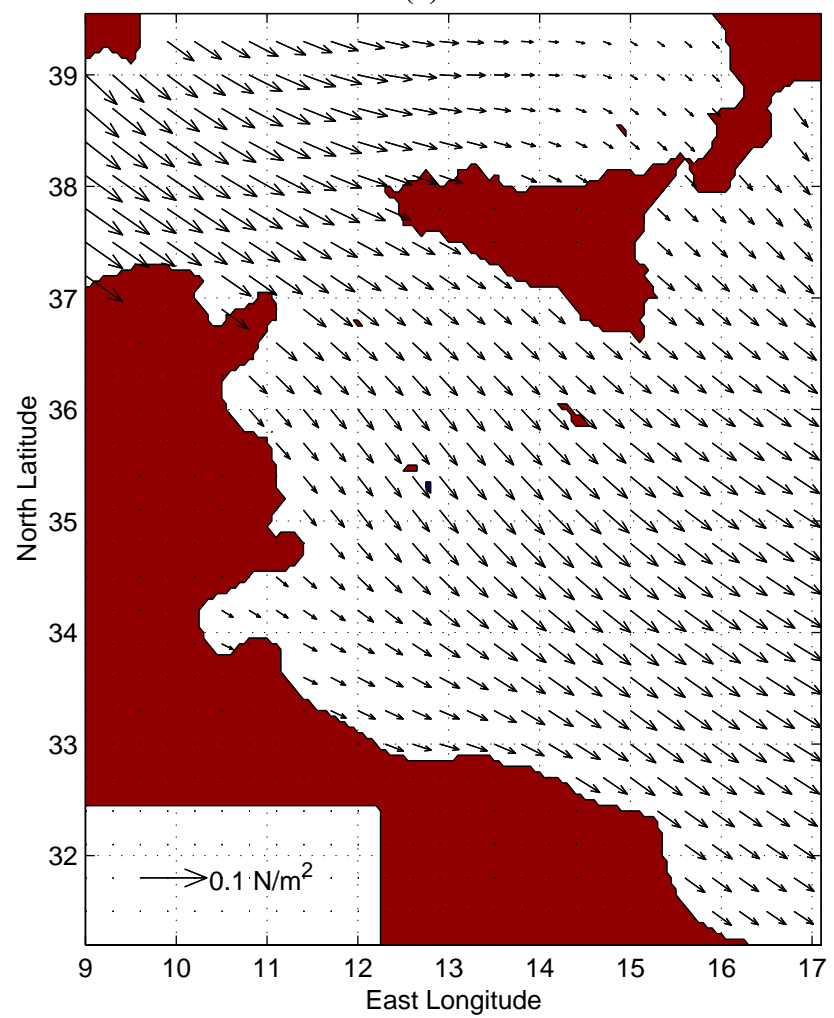

(b)

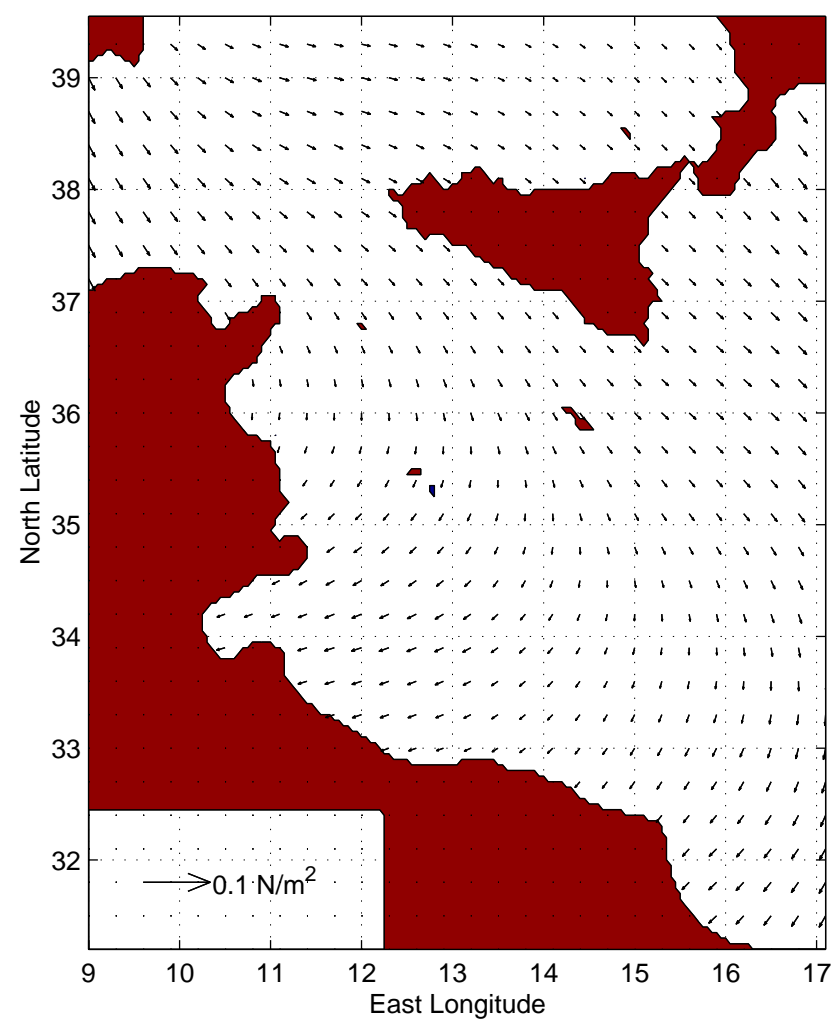

Fig. 3. The monthly averaged wind stress fields in (a) February and (b) August derived from the ECMWF Re-Analysis (ERA) data set covering the period from Jan. 1979 - Dec. 1993. One vector every four grid points is plotted. Units are $\mathrm{N} / \mathrm{m}^{2}$. model. The open boundary data are applied to the high resolution model by linearly interpolating 10-day averaged consecutive fields.

\subsection{Surface and bottom boundary conditions}

At the free surface, the climatological atmospheric forcing fields are the same as those used for the coarse model. This atmospheric forcing data set consists of heat and water flux fields, and wind stress components, on a monthly basis, derived from the European Center for Medium Weather range Forecast 6-hourly Re-Analysis (ERA) data set covering the period 1979-1993 for the whole Mediterranean Sea (Korres and Lascaratos, 2003). These fields are interpolated into the model grid using a bi-linear interpolation scheme.

The surface boundary conditions include the momentum, heat and net volume fluxes. The momentum surface boundary condition adopted is:

$\left.K_{M} \frac{\partial \boldsymbol{u}}{\partial z}\right|_{z=\eta}=\frac{\boldsymbol{\tau}}{\rho_{0}}$

where $\boldsymbol{\tau}$ is the wind stress monthly mean climatology and $\rho_{0}$ is the air density. Figure 3 shows the wind stress fields obtained from the ERA data set in February and August. The structure of the wind stress over the basin is mainly westerly during winter, with a weakening in summer. The annual cycle of the mean east-west and north-south ERA wind stress amplitudes (Fig. 4), used for the perpetual year simulation, does not contain stochastic components such as from variabilities associated with low pressure systems. This is a consequence of the use of a climatological forcing obtained by using a time series with a length of 14 years.

The adopted heat flux boundary condition is:

$$
\begin{aligned}
& \left.K_{H} \frac{\partial T}{\partial z}\right|_{z=\eta}=\frac{\left(Q_{\text {sol }}-Q_{\mathrm{up}}\right)}{\rho_{0} C_{p}}+\frac{C_{1}}{\rho_{0} C_{p}}\left(T_{z=0}^{\star}-T_{z=\eta}\right) \\
& C_{1}=\frac{\partial Q}{\partial T}=5 \mathrm{Wm}^{-20} C^{-1}
\end{aligned}
$$

where $Q_{\text {sol }}$ is the solar radiation monthly mean from ERA, $Q_{\text {up }}$ is the upward heat flux computed from the coarse model perpetual year simulation and $C_{p}$ is the specific heat capacity at constant pressure. The annual cycle of these components is shown in Fig. 5. The second term in Eq. (16) is the flux correction term, where $T_{z=0}^{\star}$ is the monthly averaged climatological sea surface temperature from the Med6 data set and $T_{z=\eta}$ is the model first level temperature. Sensitivity studies performed on the model indicate an optimal value for $C_{1}$ equal to $5 \mathrm{Wm}^{-2}{ }^{0} \mathrm{C}^{-1}$. In this way the heat flux is forced to produce a sea surface temperature consistent with the Med6 monthly climatology. The Med6 monthly mean sea surface temperature and salinity are based on the MEDATLAS data set using the MODB analysis technique (Brasseur et al., 1996).

Similarly for the salinity flux boundary condition, a correction term is used to ensure that the fresh water flux produces a sea surface salinity field consistent with the ERA 

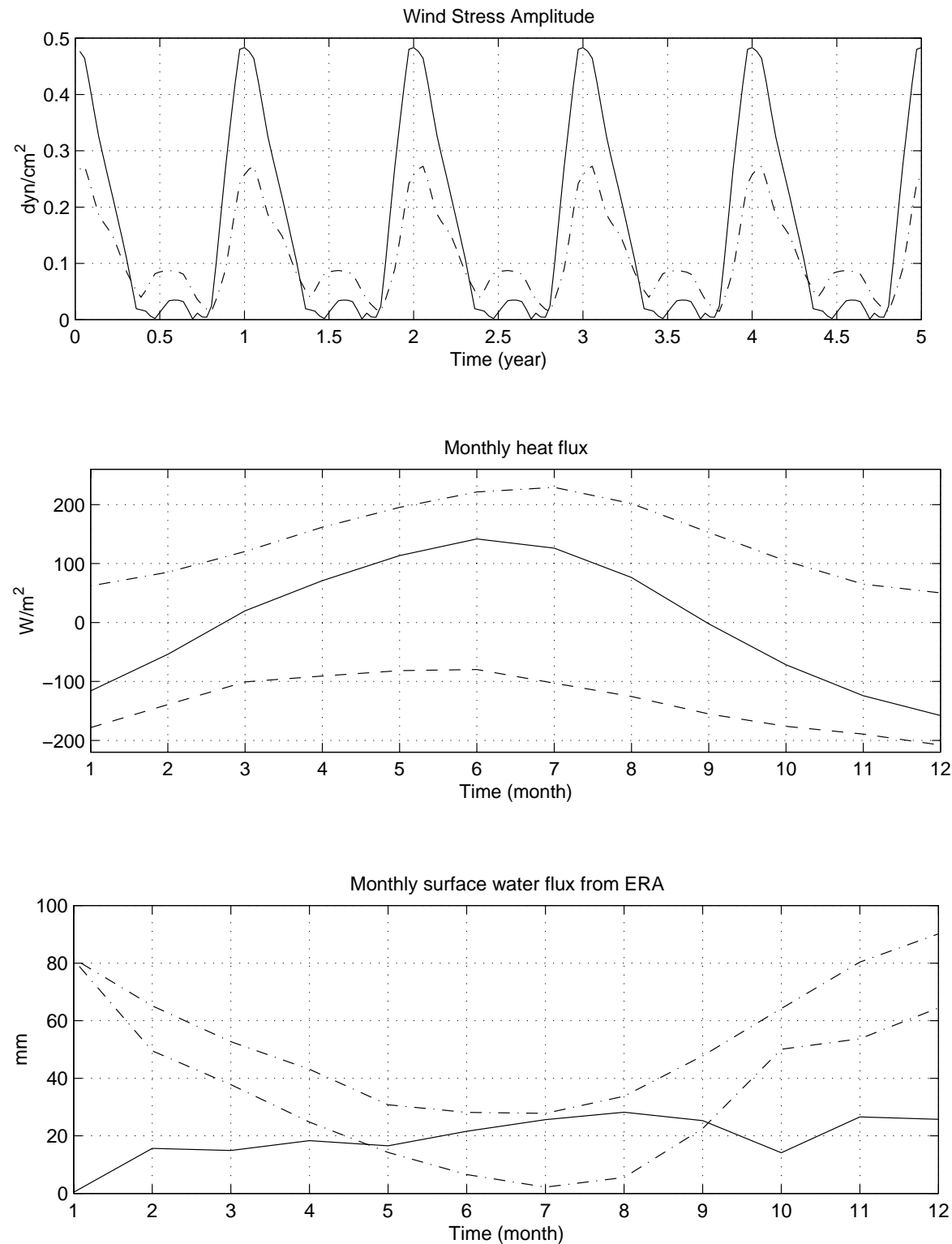

Fig. 4. The perpetual annual cycle of the east-west (solid line) and northsouth (dashdot line) mean ERA wind stress components. Units are dyne $/ \mathrm{cm}^{2}$.

Fig. 5. Annual cycle of the total heat flux (solid line), solar radiation from ERA (dash-dot line) and the upward heat flux (dashed line). Units are $\mathrm{W} / \mathrm{m}^{2}$.

Fig. 6. Annual cycle of the total freshwater flux (E-P) (solid line), evaporation (dash-dot line) and precipitation (dashed line) from the ERA data set. Units are $\mathrm{mm} / \mathrm{month}$. monthly climatology, thus:

$$
\begin{aligned}
& \left.K_{H} \frac{\partial S}{\partial z}\right|_{z=\eta}=S(E-P)+C_{2}\left(S^{\star}-S\right) \\
& C_{2}=\Delta \sigma(1) \frac{H}{\alpha}
\end{aligned}
$$

where $S$ is the model salinity at the first level, $E$ is the evaporation rate, and $P$ is the precipitation. The monthly evaporation values are computed by Korres and Lascaratos (2003) according to:

$E=\frac{Q_{e}}{L_{E}}$

where $Q_{e}$ is the latent heat flux and $L_{E}$ is the latent heat of vaporisation. The monthly precipitation data are obtained from Legates and Wilmott (1990). The annual cycle of these components is shown in Fig. 6. The last term in Eq. (18) is the salinity flux correction, where $S_{z=0}^{\star}$ is the monthly mean sea climatological surface salinity from Med6, $\Delta \sigma(1) H$ is the thickness of the surface layer and $\alpha$ is the relaxation time. In this study, the value $C_{2}$ has been chosen to be equal to $0.7 \mathrm{~m} /$ day. The correction term accounts for the imperfect knowledge of $E-P$, especially of $P$. All the monthly forcing fields $\left(\tau, T^{\star}, S^{\star}, Q_{s o l}, E\right.$ and $\left.P\right)$ are linearly interpolated between adjacent months. $Q_{\text {up }}$ is linearly interpolated between adjacent 10-day averaged fields. At the ocean bottom the boundary condition is based on a quadratic drag formulation.

In Sect. 4 the general circulation in the Central Mediterranean and its seasonal variability are discussed from model output during the last year of integration of the 5-year perpetual simulation. 
(a)

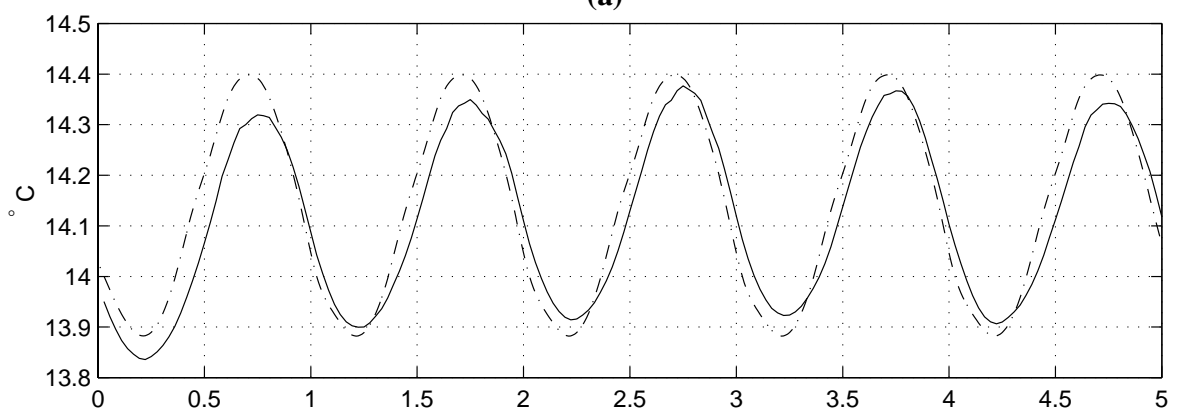

(b)

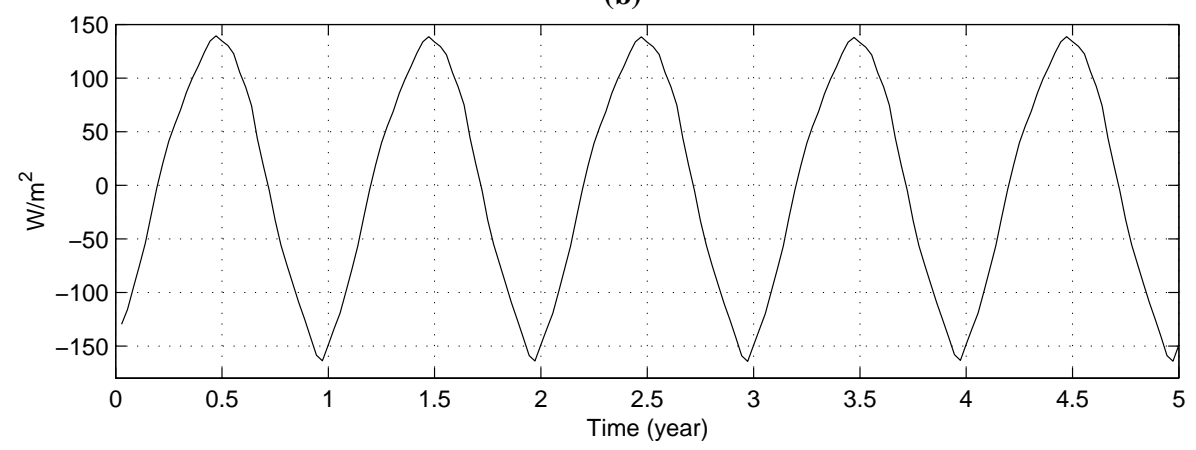

(a)

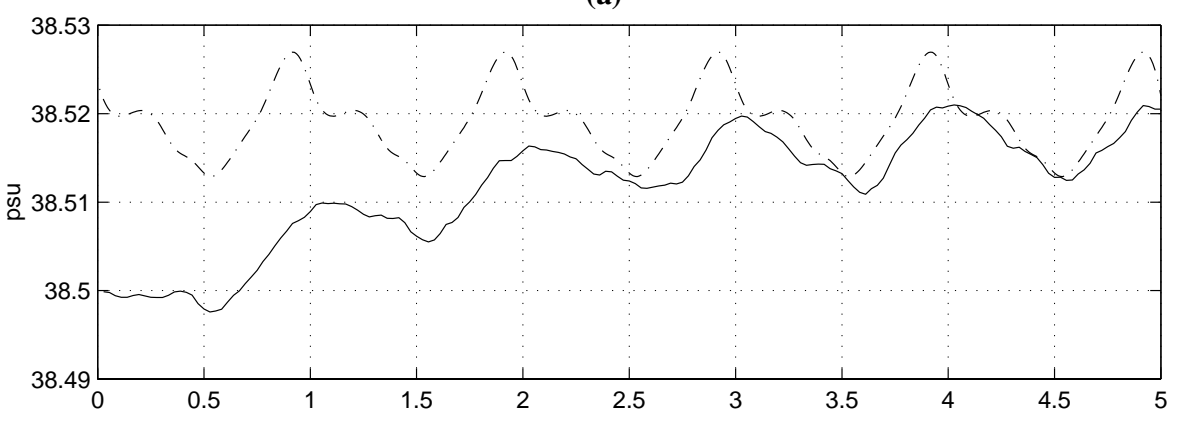

(b)

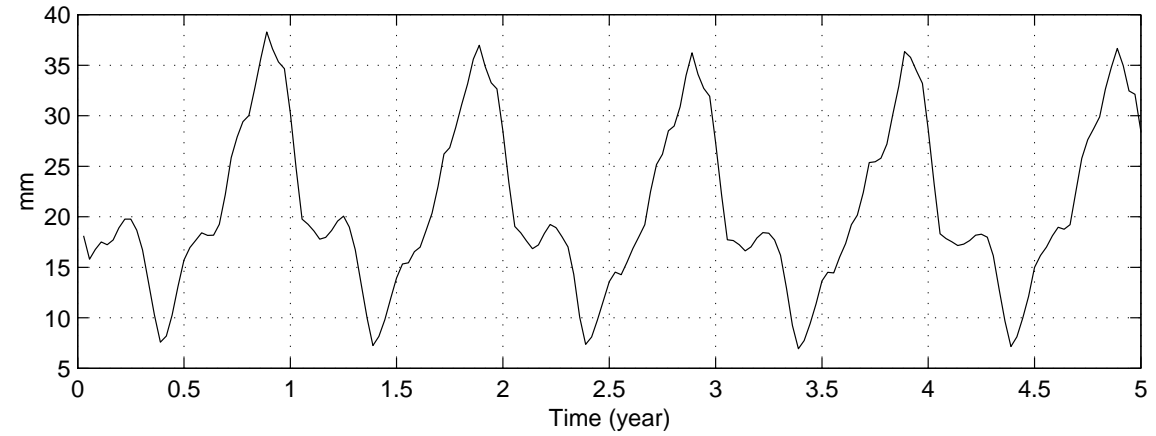

Fig. 7. (a) Comparison between the modelled (solid line) and Med6 climatology (dash-dot line) time series of potential temperature; Units are ${ }^{\circ} \mathrm{C}$. (b) Time series of the modelled total heat flux; Units are $\mathrm{W} / \mathrm{m}^{2}$.
Fig. 8. (a) Comparison between the modelled (solid line) and Med6 climatology (dotted line) time series of salinity; Units are psu. (b) Time series of the modelled surface water flux. Units are $\mathrm{mm} / \mathrm{month}$.

\section{Results}

Starting from 1 January, the model is integrated for five successive years with surface and lateral boundary conditions, as described in Sect. 3. The model output is first described in terms of the time evolution of key parameters, namely the basin mean of temperature and salinity, and the mean superficial heat and water fluxes, which are plotted from 10-day averaged values. The simulated horizontal fields at $5 \mathrm{~m}$ and $280 \mathrm{~m}$ depth, and vertical sections along the meridians $9^{\circ} \mathrm{E}$, $13^{\circ} \mathrm{E}$ and between $11.1^{\circ} \mathrm{E}-36.85^{\circ} \mathrm{N}$ and $12.3^{\circ} \mathrm{E}-38^{\circ} \mathrm{N}$ (across the Sicily Strait), taken from the fifth year of model integration, are used to describe the phenomenology and the seasonal variability of the 3-D circulation in the model domain. The monthly mean fields of temperature, salinity and velocity for February and August are used as the representa- 
(a)

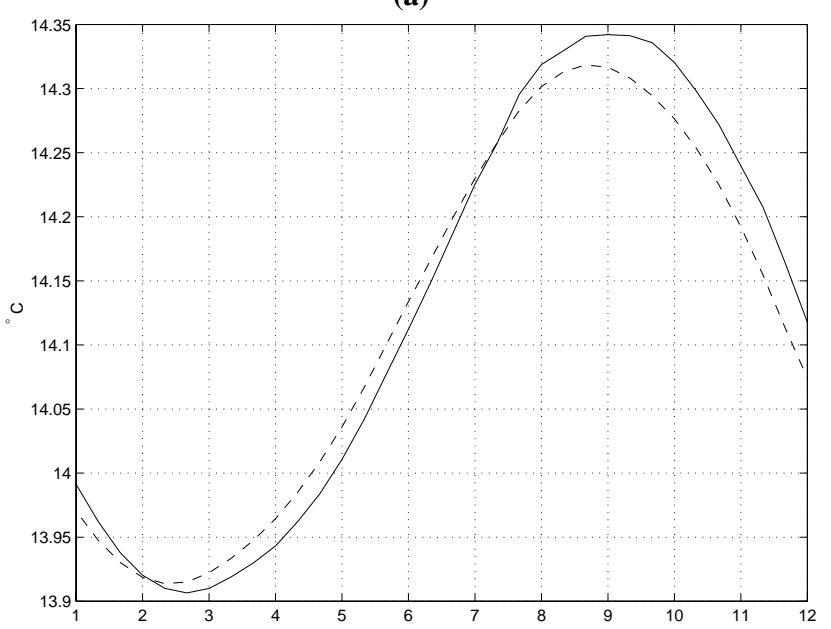

(b)

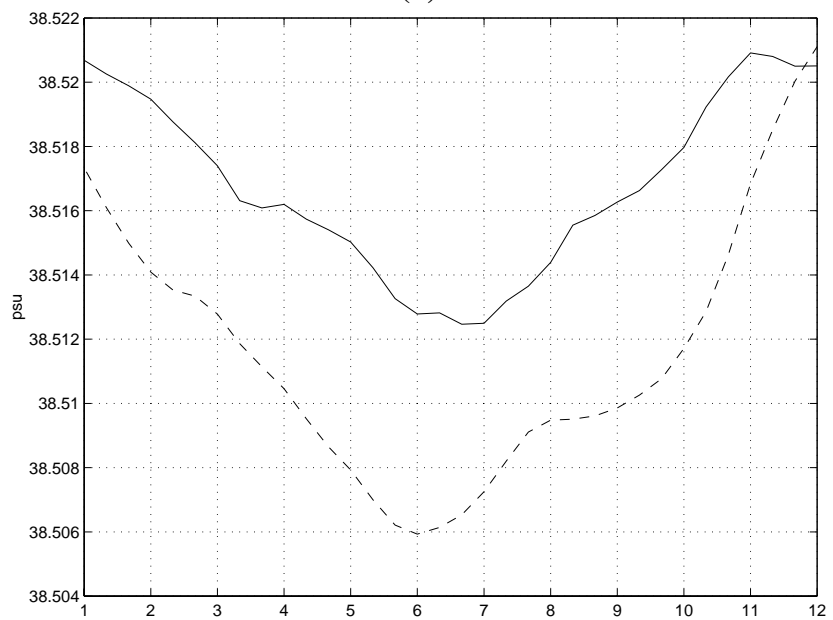

(c)

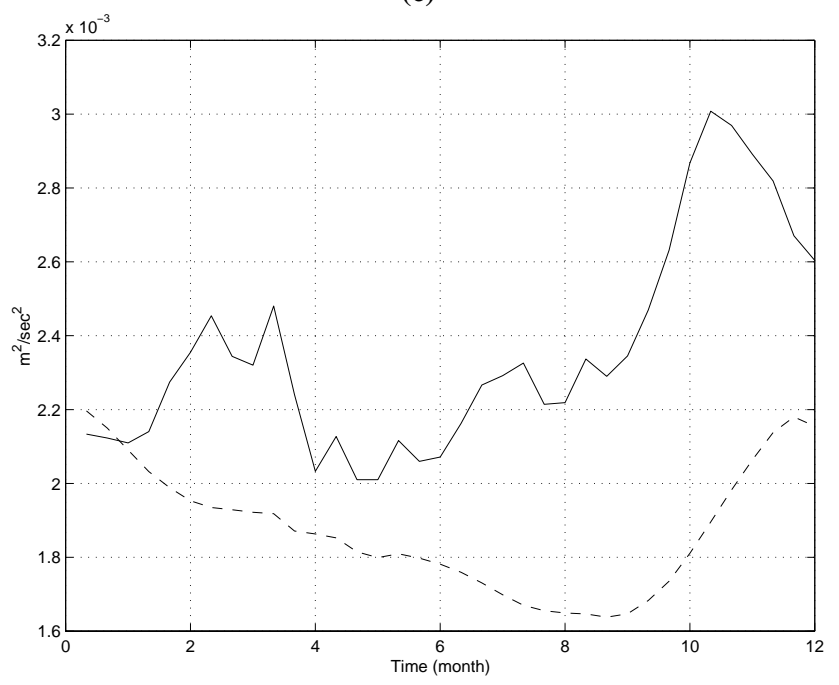

Fig. 9. Comparison between the fine resolution inner model (solid line) and the coarse resolution outer model (dashed line) by 10-day averaged time series of mean volume (a) temperature, (b) salinity and (c) total kinetic energy, calculated over the inner model domain during the last year of integration. Units are ${ }^{\circ} \mathrm{C}$, psu and $\mathrm{m}^{2} / \mathrm{s}^{2}$, respectively.

tive months for winter and summer, respectively. They depict the general characteristics of the circulation in the region, with the prevalent occurrence of sub-basin scale gyres and intense coastal boundary currents, exhibiting a high temporal and spatial variability.

\subsection{Time series}

The annual cycle of the basin mean potential temperature (Fig. 7a) has a minimum of $13.87^{\circ} \mathrm{C}$ in March and a maximum of $14.30^{\circ} \mathrm{C}$ in September. The model replicates well the Med6 climatology, although the range is slightly less and a small phase shift is introduced. The temperature extremes occur at about three months after the corresponding extremes of the total superficial heat flux (Fig. 7b). This delay gives an indication of the time scales for vertical exchanges in the water column.
The annual cycle of the total superficial heat flux ranges between a minimum of $-150 \mathrm{~W} / \mathrm{m}^{2}$ (December) to a maximum of $+130 \mathrm{~W} / \mathrm{m}^{2}$ (June), summing to an annual heat budget of about $-0.8 \mathrm{~W} / \mathrm{m}^{2}$ during the last year of integration. The heat gain occurs from April to September, while heat losses are maximal in the period November-January. Similarly the extremes of the basin mean salinity (Fig. 8a) are 38.5 psu in June and 38.52 psu in December, occurring with a delay of two months with respect to the corresponding extremes of the water flux (Fig. 8b).

The annual cycle of the mean basin salinity over the five years of perpetual integration shows a slight positive trend (two orders of magnitude smaller than the salinity value) that is probably caused by the low initial salinity field derived from the coarse model with respect to the climatological mean. However, the trend tends to attenuate towards the last year of integration as the model approaches closely the 
(a)

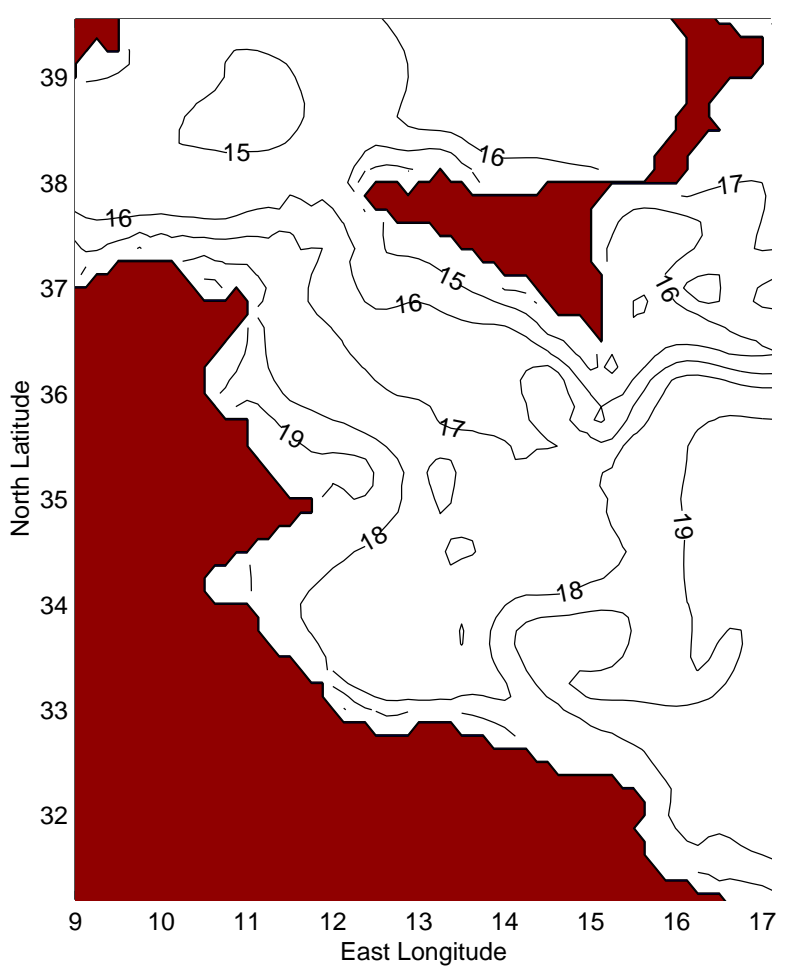

(c)

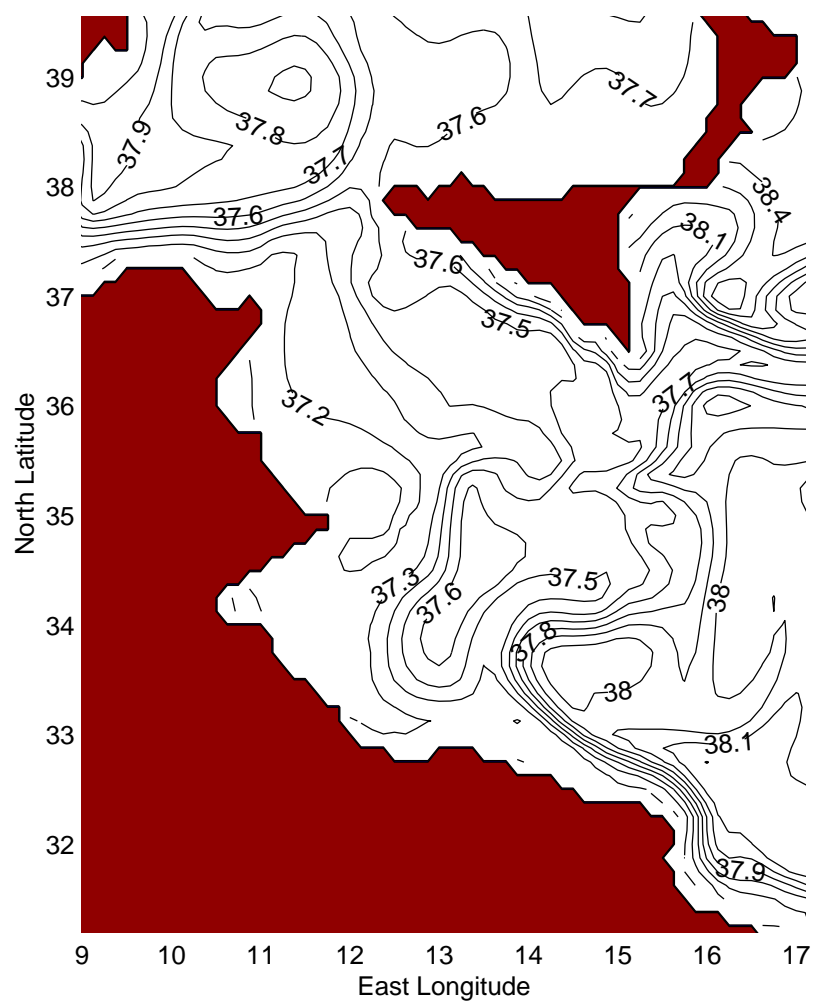

(b)

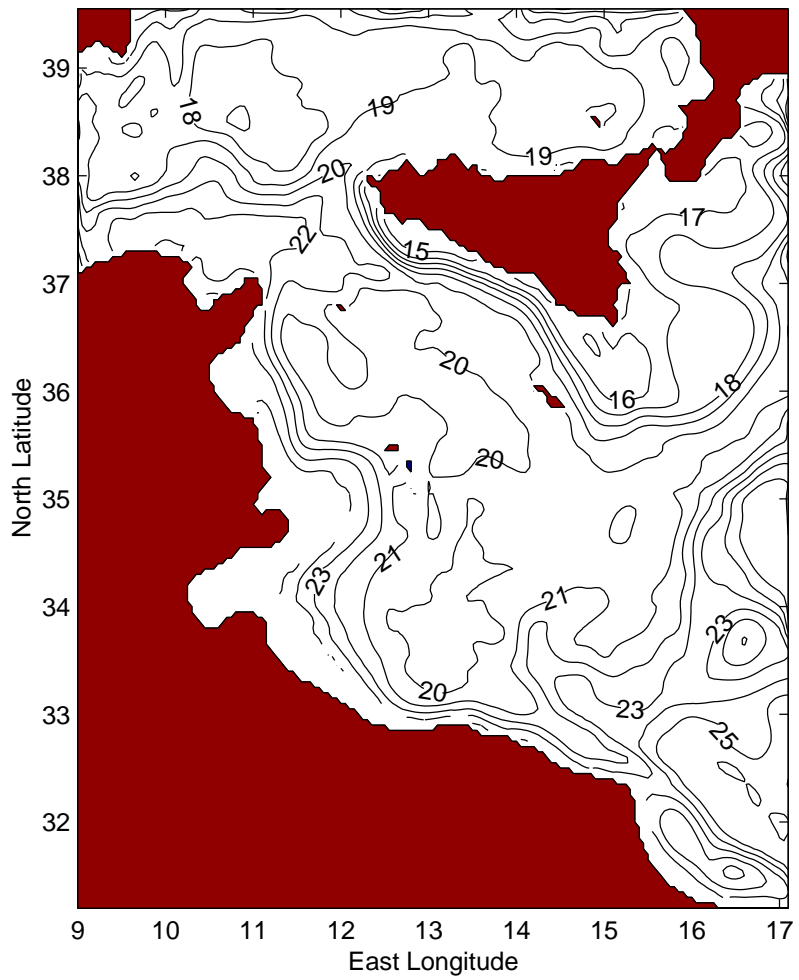

(d)

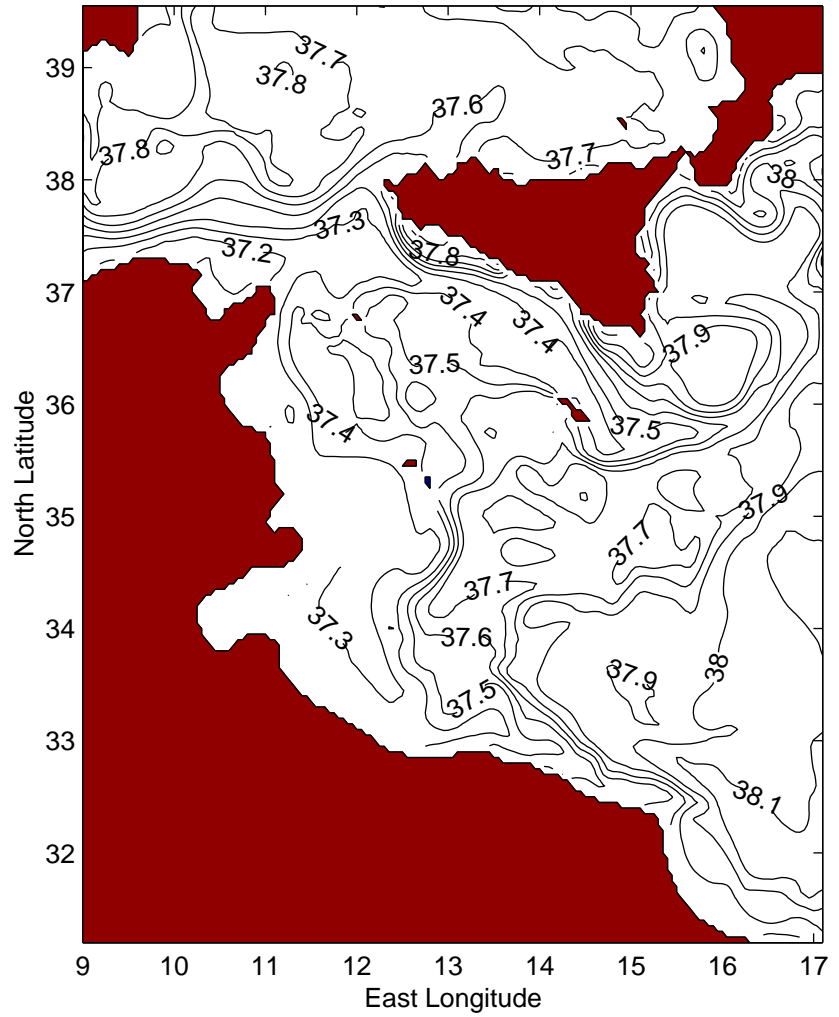

Fig. 10. Comparison of the simulated coarse outer model ((a), (c), (e)) and the fine inner model ((b), (d), (f)) using 10-day averaged temperature $(\mathrm{a}, \mathrm{b})$, salinity (c, d) and total velocity (e, f) horizontal fields at $30 \mathrm{~m}$ depth in August (Fig. 10 continues). 
(e)

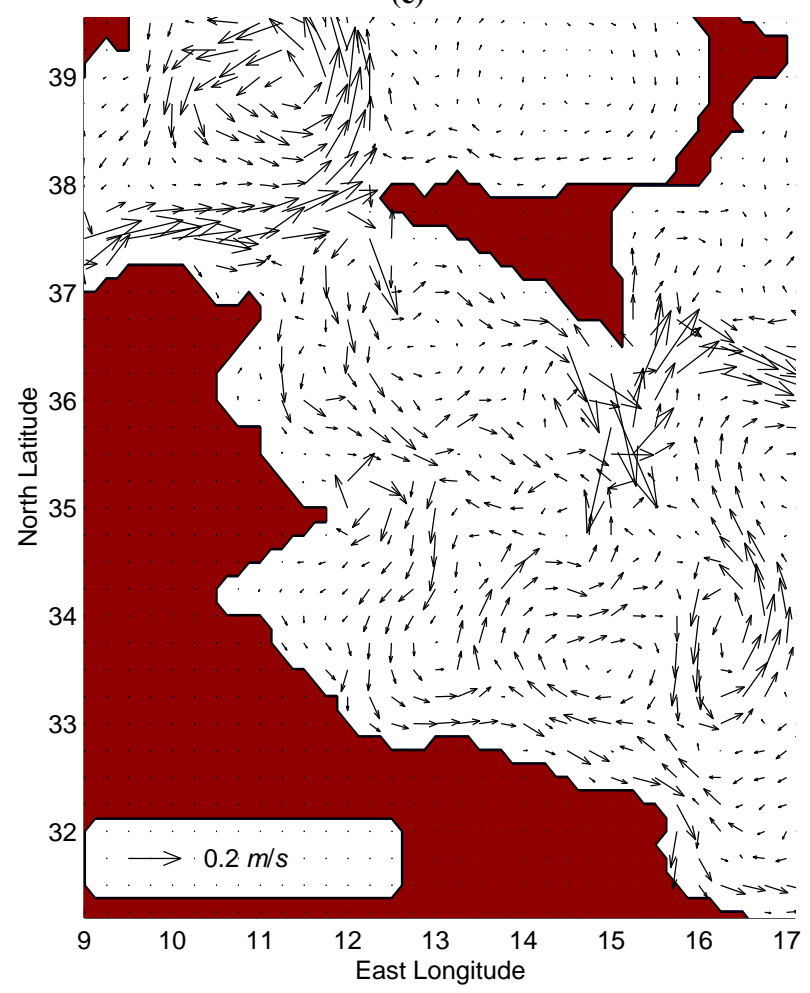

(f)

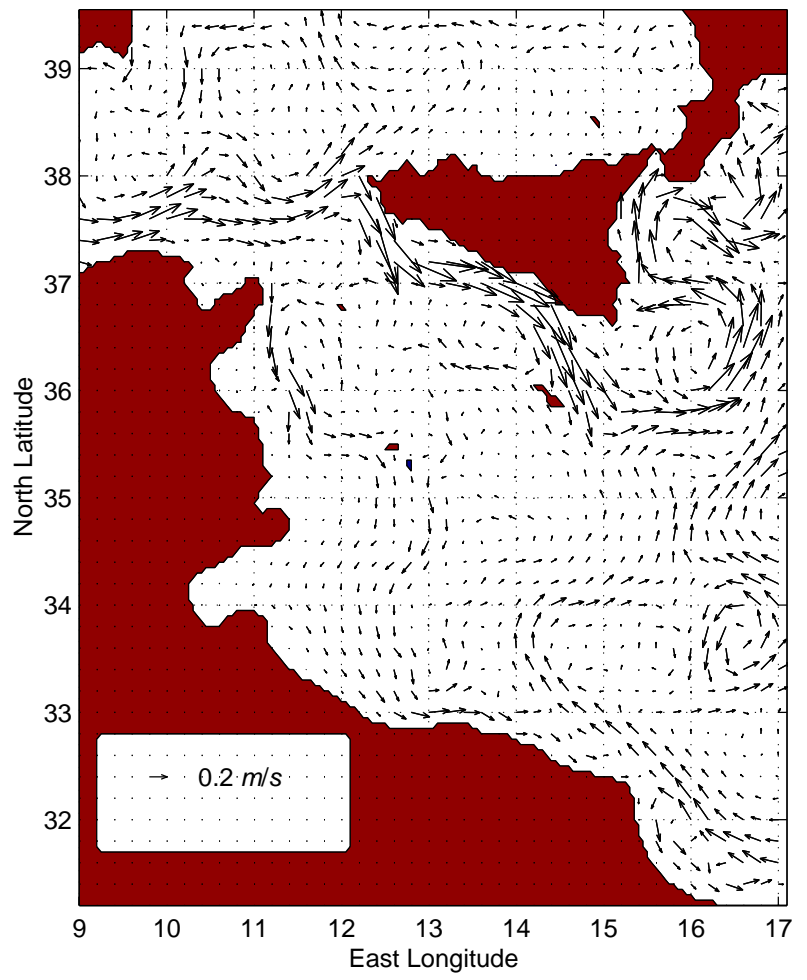

Fig. 10. ... continued.

climatological values. The water flux is always positive, resulting in an annual budget of about $+20.8 \mathrm{~mm} / \mathrm{yr}$. It fluctuates between a minimum of $+5 \mathrm{~mm}$ in May and a maximum of about $+40 \mathrm{~mm}$ in November. Thus, the seasonal cycle is characterized by values below the mean in winter, spring and summer, and by higher values during autumn.

\subsection{Model-model comparison}

The performance of the coupling between the POM fine resolution model and the OGCM-MOM coarse model can be obtained by comparing the inner model output with the benchmark basin scale OGCM model simulation calculated over the inner domain. Figure 9 is a comparative plot between the two models showing a time series of 10-day averaged values of key parameters, namely the mean volume temperature, salinity and total kinetic energy. There is a very high correlation in the mean volume temperature (Fig. 9a). The minima and maxima are very close, except for a slight phase shift. The variation of the mean volume salinity in time is close to that of the coarse resolution model, except for a shift of 0.01 psu (Fig. 9b). For the total kinetic energy, the correlation is lower especially in the period April to November, when the AIS flow magnitude in the inner model implementation is somewhat higher. This assessment quantifies the robustness of the nested-grid technique used in the numerical experiment.

A visual match between the two models can be further made by the comparison plots of the horizontal fields of temperature (Fig. 10a, b), salinity (Fig. 10c, d) and total velocity (Fig. 10e, f) at $30 \mathrm{~m}$ depth. The example is taken from values averaged over the first 10 days of August. Such a comparison is useful to verify the ability of the inner fine model to replicate in space the principal hydrodynamical features of the outer coarse model. Moreover, they show the merit of the fine grid model in improving the resolution of the mesoscale detail, amplifying or attenuating particular structures that characterize the simulated flow details in the area. Although the level of compatibility between the two model solutions varies in time, it is evident that the high resolution model is able to reproduce well the AIS flow and variability, including the associated characteristic structures such as the Adventure Bank Vortex, the Maltese Channel Crest, the Ionian Bank Vortex and the overshooting into the northern Ionian Sea. Moreover, the sigma-coordinate vertical discretisation used in the fine resolution model results in an improved simulation of the upwelling phenomena along the southern coast of Sicily, and gives a generally improved description of the water dynamics in the shallow areas. In the POM inner model the number of vertical sigma levels is independent of the depth; this means that in shallow water, such as, for example, at depths of less than $35 \mathrm{~m}$, the vertical column of water in the coarse resolution model is simulated by only three levels, at 5,15 and $30 \mathrm{~m}$, whereas in the fine resolution model the same maximum number of vertical levels is utilized at all depths. 
(a)

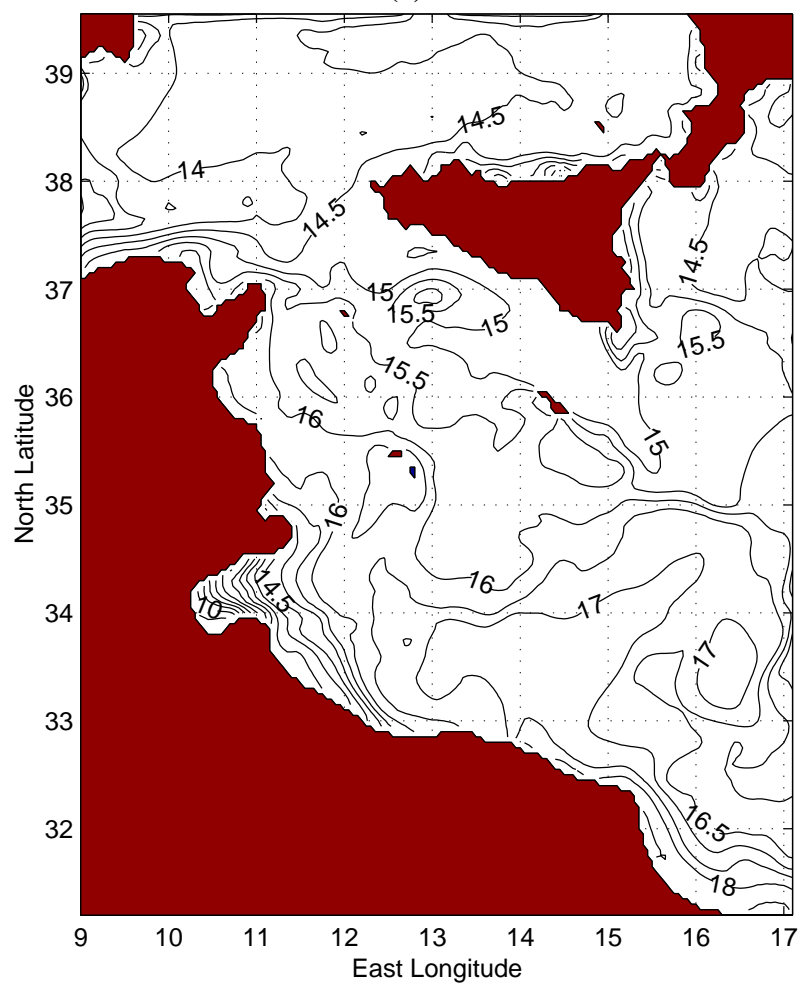

(b)

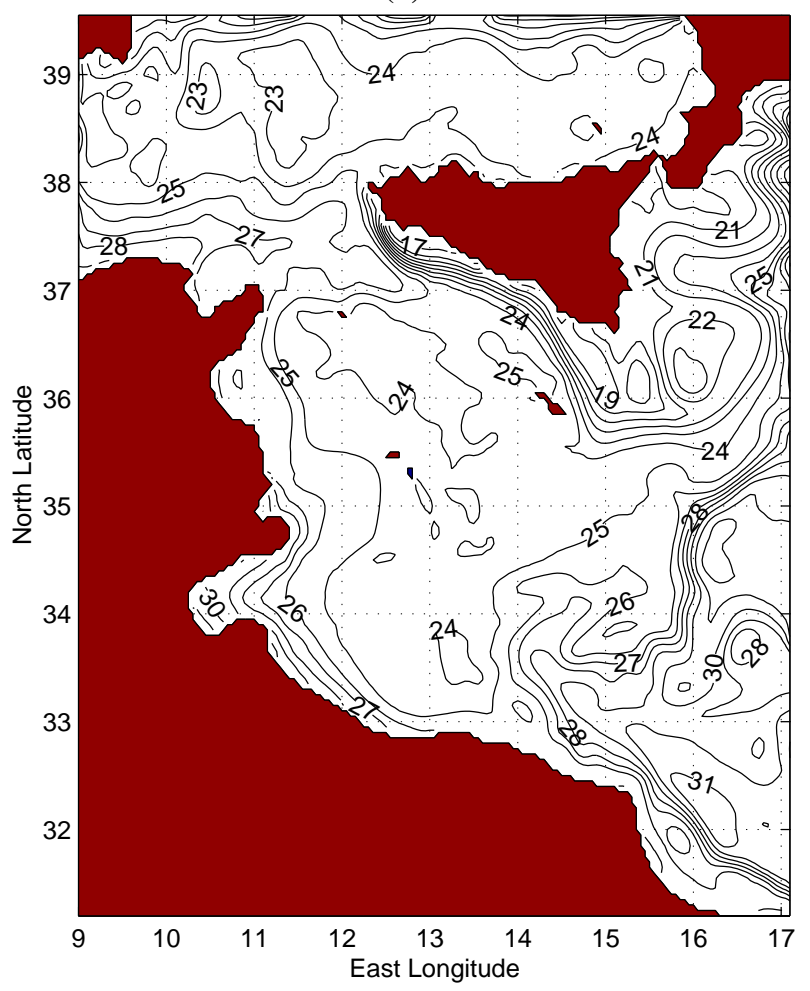

Fig. 11. The simulated 10-day averaged temperature field at $5 \mathrm{~m}$ depth in (a) February and (b) August. The contour interval is $0.5^{\circ} \mathrm{C}$ in February and $1^{\circ} \mathrm{C}$ in August.

(a)

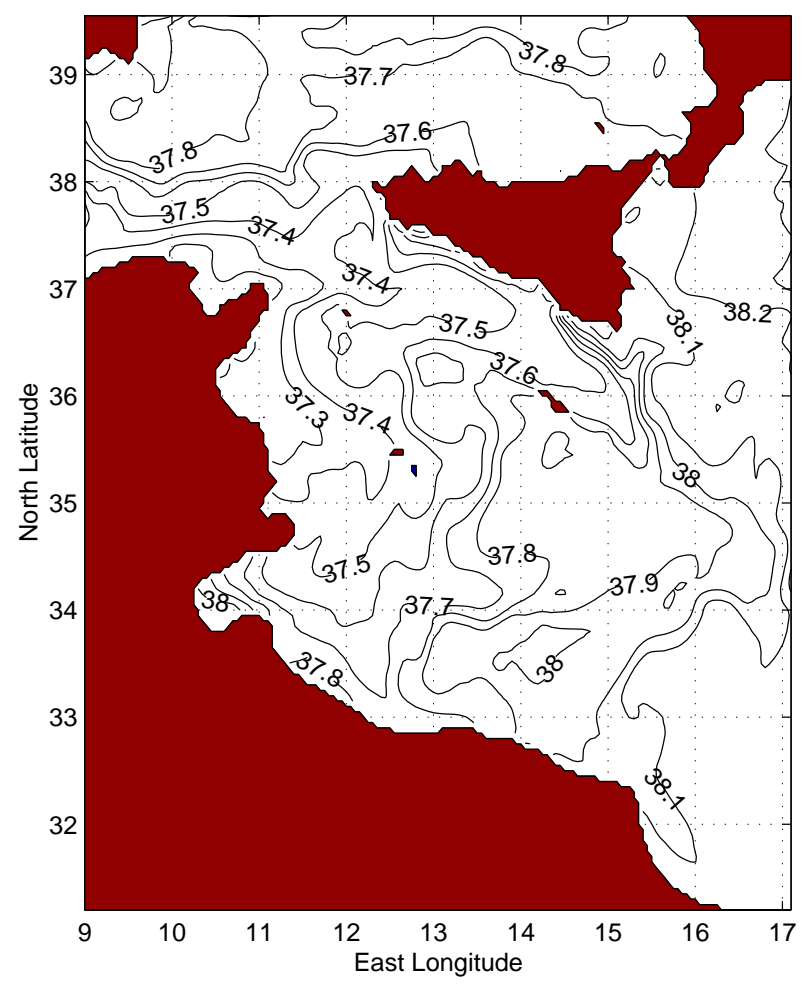

(b)

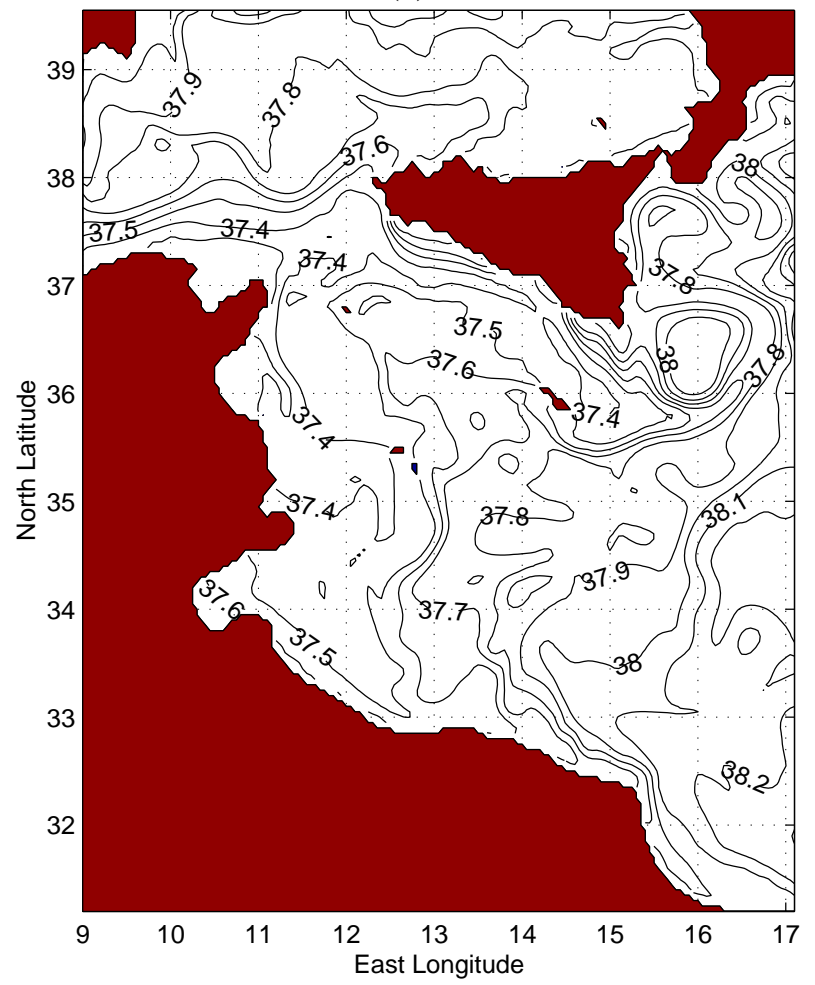

Fig. 12. The simulated 10-day averaged salinity field at $5 \mathrm{~m}$ depth in (a) February and (b) August. The contour interval is $0.1 \mathrm{psu}$. 
(a)

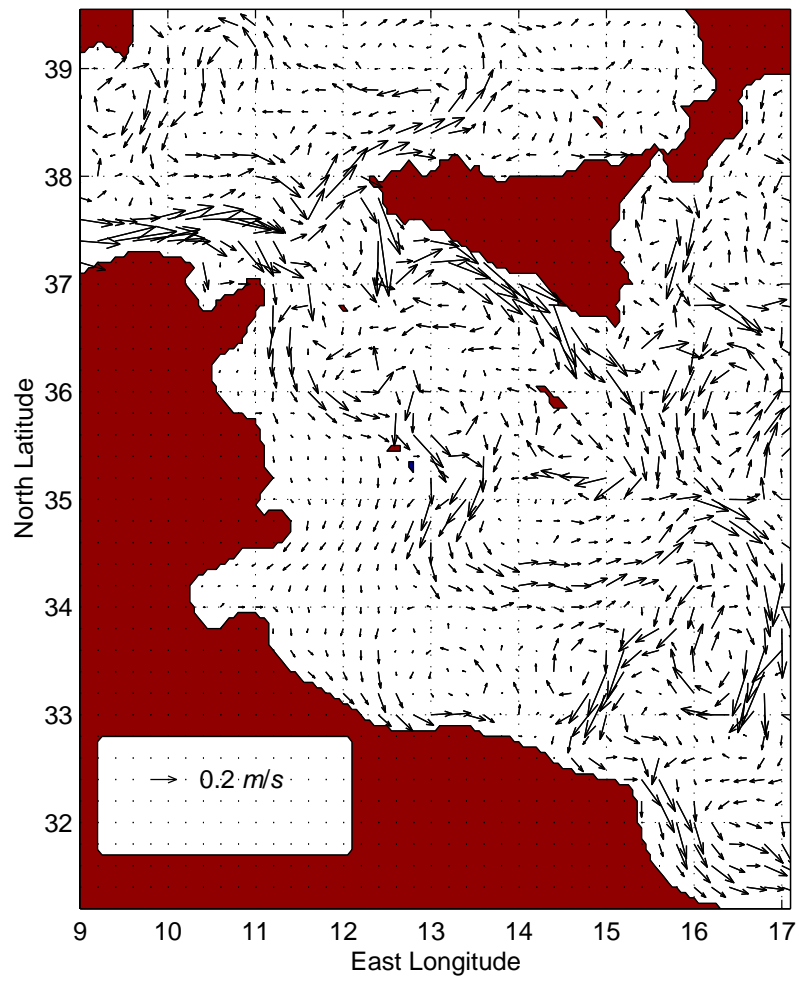

(b)

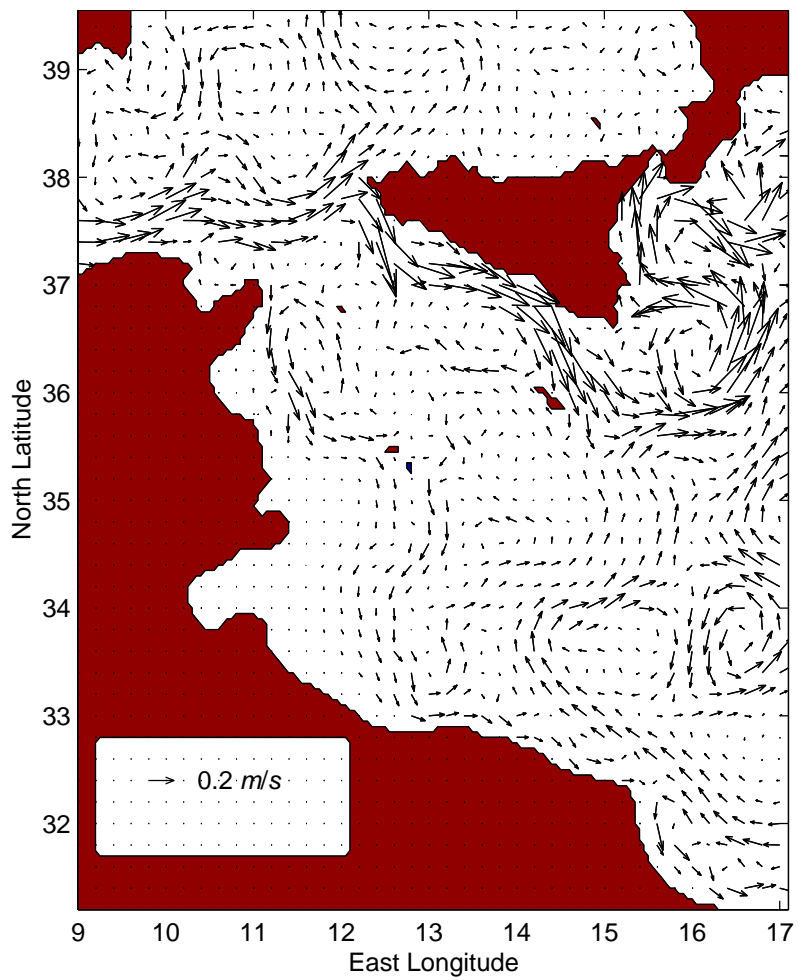

Fig. 13. The simulated 10-day averaged total velocity field at $5 \mathrm{~m}$ depth in (a) February and (b) August. One vector every four grid points is plotted. Units are m/s.

The difference in the performance is evident in Fig. 10 where it is noted that in the coarse resolution model the zone of upwelled waters appears rather displaced from the Sicilian coast and limited to a rather narrow coastal band. Another important improvement is the capacity of the fine resolution model to reduce the occurrence of high velocities produced by the coarse model, such as on the Adventure Bank and the Malta shelf area.

In the following sections, the skill of the model is further evidenced by the high level of agreement of the simulated flow field with the known circulation patterns described in Sect. 2. This is a main achievement of this work when compared to other previous modelling experiences covering this part of the Mediterranean. On this basis the model results can be very confidently utilized to furnish a first detailed description of the circulation pertaining to this region, with insight on its variability in both space and time.

\subsection{Surface circulation}

The upper ocean flow is dominated by the eastward bound MAW moving under the influence of the density gradient between the eastern and western basins, and modified by the influence of the wind forcing and the bottom geometry. The simulated seasonal potential temperature fields at $5 \mathrm{~m}$ depth are presented by comparison of the winter and summer situations (Fig. 11), using 10-day averaged fields. This shows a shift in the mean temperature of about $6^{\circ} \mathrm{C}$ between February and August, mainly as a consequence of surface heating. During winter, the thermal structure is fairly homogeneous, especially beyond $35^{\circ} \mathrm{N}$ (in the Sardinia Channel, the south Tyrrhenian Sea and the north side of the Sicily Channel). In these regions the temperature does not exceed $15^{\circ} \mathrm{C}$. Warmer waters are found on the African side. In summer the simulated potential temperature is characterized mainly by upwelling events along the southern coast of Sicily, bringing cooler water to the surface. This is in contrast to the overall increase in temperature over the region. Warm waters, with a mean temperature of over $26^{\circ} \mathrm{C}$, are found on the southeastern side of the domain. The simulated 10-day averaged salinity and total velocity fields at $5 \mathrm{~m}$ depth (Figs. 12 and 13, respectively) show the seasonal signature of the MAW flow which can be followed as an extension of the Algerian coastal current into the Sicilian Channel and beyond as an unstable flux of relative fresh water. It is identified by a salinity in the range from 37.2 to $37.7 \mathrm{psu}$, and its horizontal variation shows the gradual modification of its properties as it penetrates from west to east across the domain.

\subsubsection{The Sardinia Channel region}

In the Sardinia Channel region, the MAW flow enters across the section at $9^{\circ} \mathrm{E}$ as a broad, homogeneous layer whose characteristics change with time, especially with respect to 
(a)

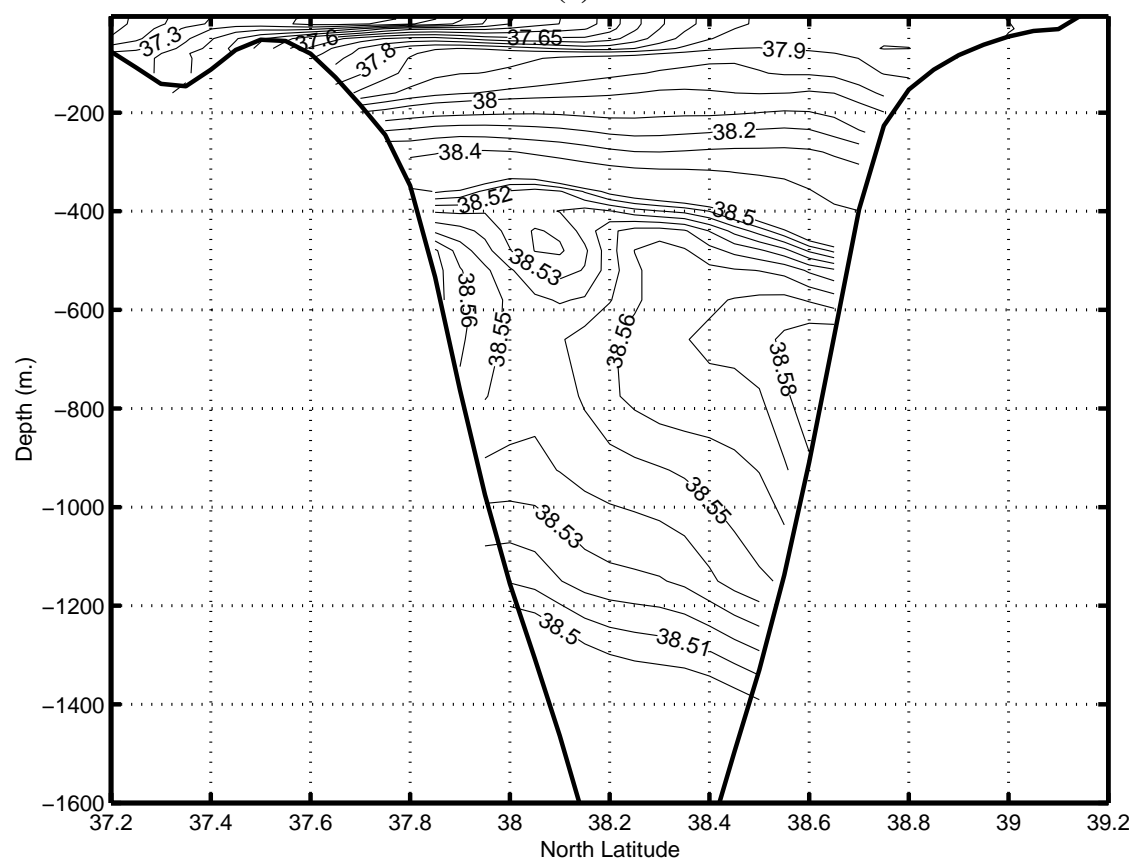

(b)

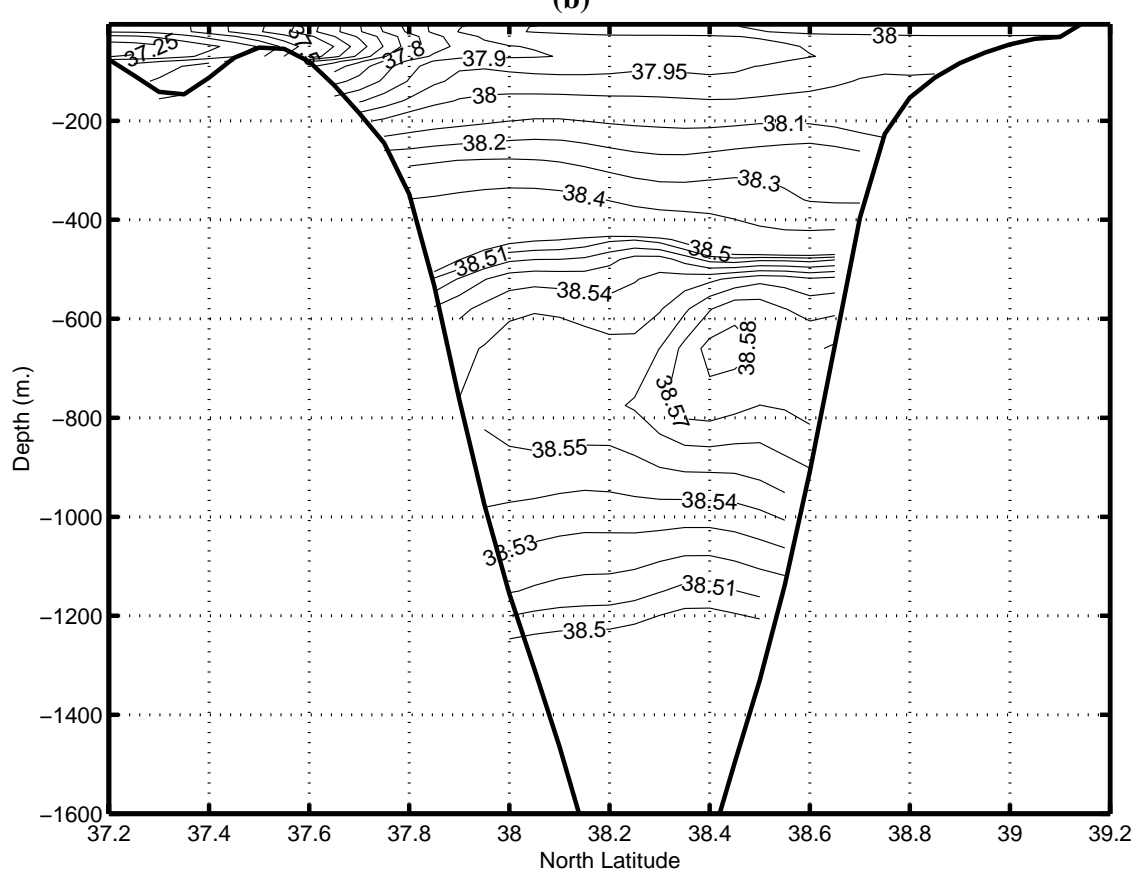

Fig. 14. The simulated 10-day averaged vertical section of salinity along longitude $9^{\circ} \mathrm{E}$ in (a) February and (b) August. The contour interval is $0.05 \mathrm{psu}$ in the range 37.0 to $38.5 \mathrm{psu}, 0.01$ in the range between 38.0 to 38.5 and 0.02 in the range 38.5 to 38.6 psu.

layer width and core depth. The vertical sections of the simulated salinity (Fig. 14a) show the inflow of the MAW close to the Tunisian coast, as a superficial layer characterized by a minimum salinity of about 37.2 psu and speeds reaching up to $45 \mathrm{~cm} / \mathrm{s}$ during the period November to March. In November 1993, Bouzinac et al. (1999) have calculated a maximum eastward velocity of over $30 \mathrm{~cm} / \mathrm{s}$ at the salinity minimum situated at $800 \mathrm{dbar}$, indicating flow characteristics typical of an alongshore frontal current. Toward the summer months (Fig. 14b), the MAW flow is progressively eroded from the surface, with a decrease in speeds, becoming a subsurface core from July to October, and with a minimum of salinity at a depth between $50-80 \mathrm{~m}$. According to the model, the eastern volume transport along the section at $9^{\circ} \mathrm{E}$ reaches its 


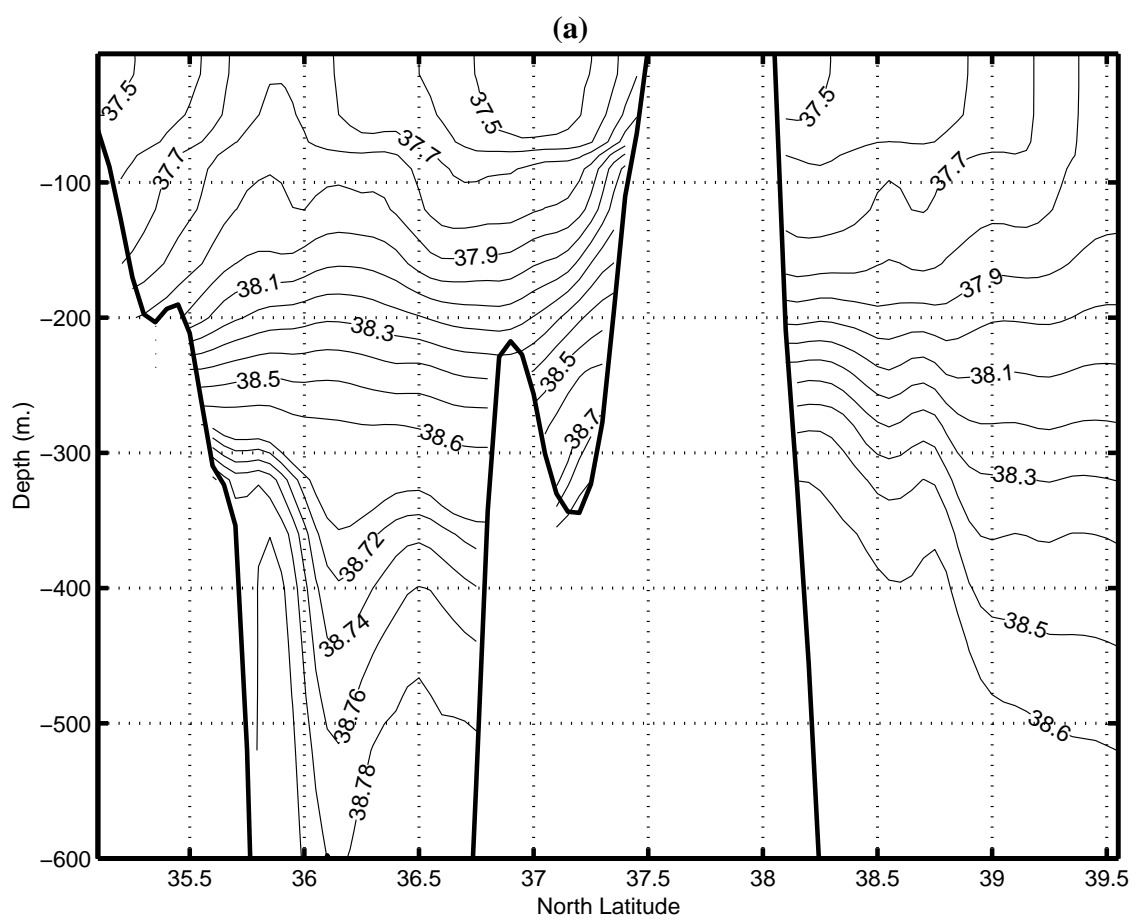

(b)

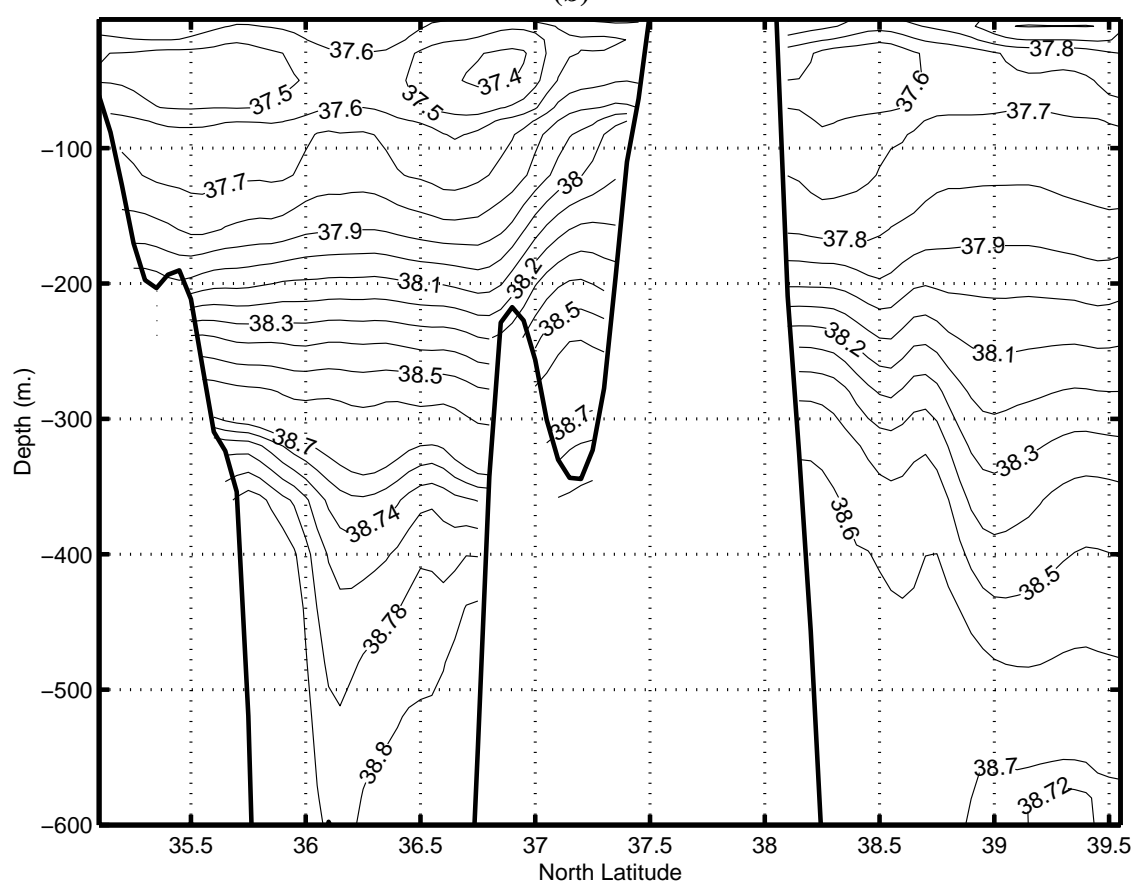

Fig. 15. The simulated 10-day averaged vertical section of salinity along longitude $13^{\circ} \mathrm{E}$ in (a) February and (b) August. The contour interval is $0.1 \mathrm{psu}$ in the range 37.4 to $38.7 \mathrm{psu}$, and $0.02 \mathrm{psu}$ in the range from 38.7 to $38.8 \mathrm{psu}$.

lowest value of about $2.5 \mathrm{~Sv}$ between July/August, while it increases again in the winter months, with a maximum of over 2.0 Sv from November to May (not shown). Prior to the Strait of Sicily, the lateral variation in density between the MAW and the surrounding waters, together with strong differences in the velocity shear, renders the MAW stream highly unstable, and results in the generation of rather energetic eddies. These have length scales of about $50-100 \mathrm{~km}$ and periods of a few months. They are believed to play an important role in the transfer of MAW into the Tyrrhenian Sea. Krivosheya (1983), Astraldi and Gasparini (1994) describe a permanent cyclonic gyre rotating over the southeast- 
(a)

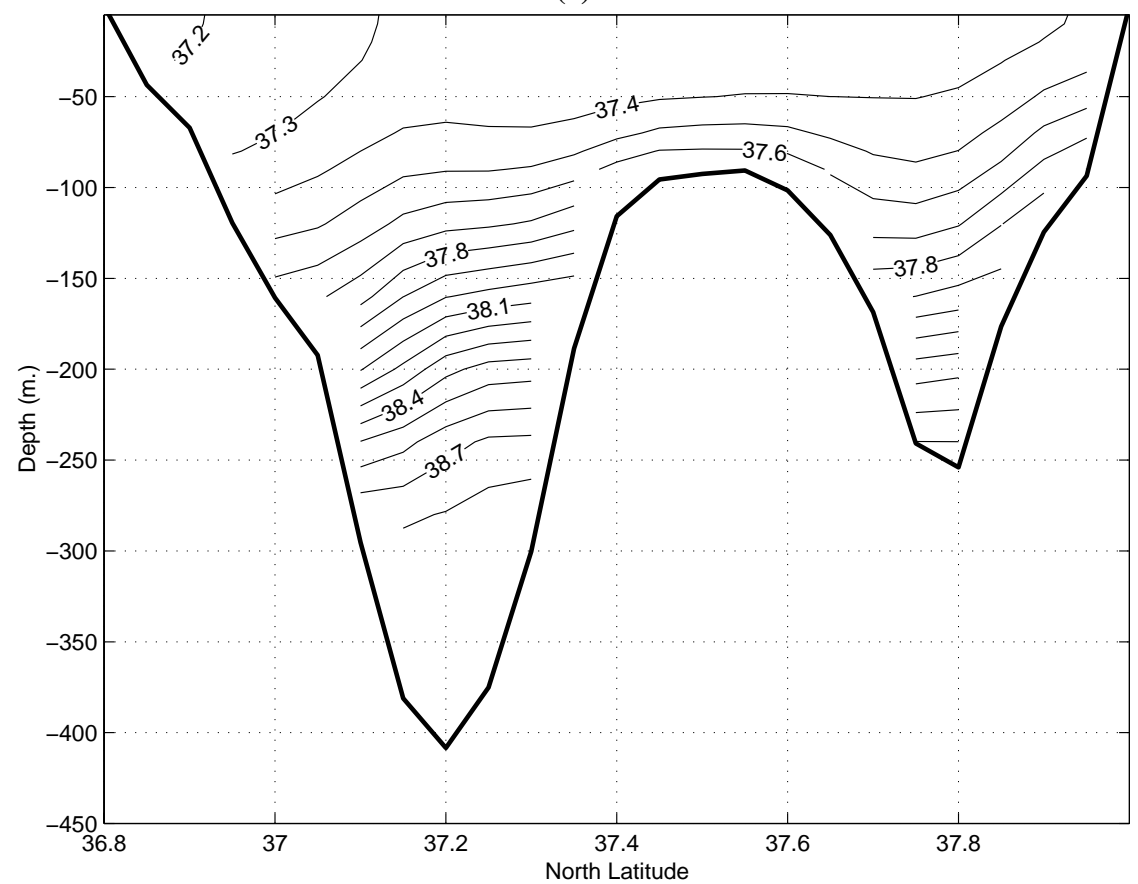

(b)

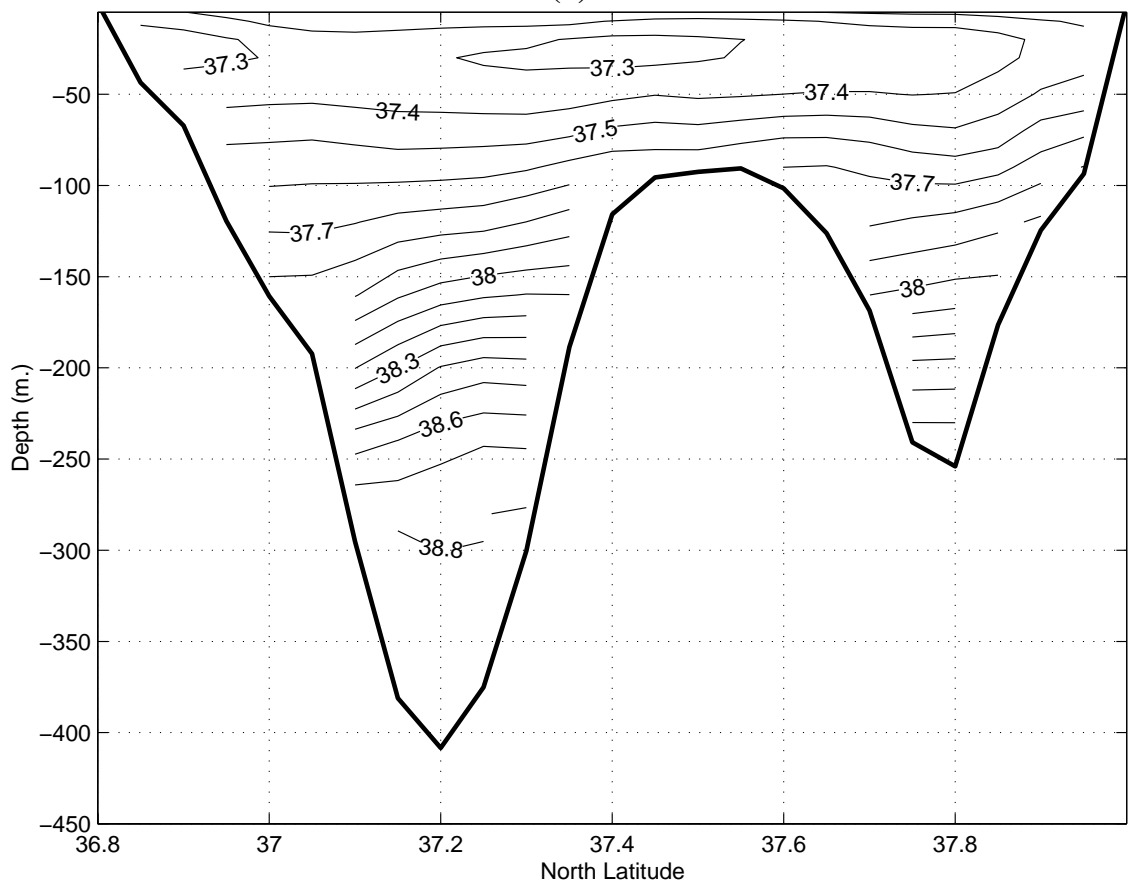

Fig. 16. The simulated 10-day averaged vertical section of salinity across the section from $11.1^{\circ} \mathrm{E}$ and $36.85^{\circ} \mathrm{N}$ (Tunisia) to $12.3^{\circ} \mathrm{E}$ and $38.0^{\circ} \mathrm{N}$ (Sicily) in (a) February and (b) August. The contour interval is 0.1 psu.

ern coast of Sardinia. The model replicates the presence of such a gyre centered at about $11^{\circ} \mathrm{E}$ and $38.5-39^{\circ} \mathrm{N}$, exciting an intense recirculation of the MAW, particularly in summer (Fig. 13). The branching of the MAW flow into two main streams is also well evidenced by the model results. The first follows the northern Sicilian shelf and spreads into the Tyrrhenian Sea, while the second, less salty, transits the Strait of Sicily towards the eastern Mediterranean basin (Astraldi et al., 1999; Manzella, 1990; Bethoux, 1980). Recently, the MAW salinity split at $11^{\circ} \mathrm{E}$ has also been confirmed by Onken and Sellschopp (2001), using data collected during a survey in the second half of October 1996. 
The inflow of MAW into the Tyrrhenian Sea has a high seasonal variability, especially in the mean and total velocities associated with the MAW stream, while the salinity is more stable. The vertical sections of the simulated salinity at $13^{\circ} \mathrm{E}$ (from $38^{\circ} \mathrm{N}$ to $39.5^{\circ} \mathrm{N}$, in the south Tyrrhenian Sea) in Fig. 15 show the eastward extension of the MAW flow to the north of Sicily as a large vein characterized by a minimum of salinity of around $37.5 \mathrm{psu}$. Speeds reach values over $20 \mathrm{~cm} / \mathrm{s}$ from December to May, while maximum velocities of up to $30 \mathrm{~cm} / \mathrm{s}$ occur in December. The isohalines are inclined toward the north Sicilian coast and the minimum salinity is located at the surface close to Sicily (Fig. 15). From May to August the MAW is progressively eroded from the surface, developing into a subsurface minimum of salinity at about $50 \mathrm{~m}$ depth, and with a decrease in speed. The isohalines tend to become horizontal, with an increase in the temperature and salinity values toward the surface, due to a positive heat exchange and negative water vapour exchange with the atmosphere.

\subsubsection{The Sicily Channel region}

The examination of the vertical sections of the simulated salinity and the total velocity fields, between Cape Bon (on the Tunisian perimeter) and the western coast of Sicily (Fig. 16), show that the presence of the MAW is characterized by a high seasonal variability in both its temperature and velocity. From November to May, the isohalines appear inclined towards the African side. The MAW flows eastward, predominantly along the Tunisian side with speeds reaching up to $30 \mathrm{~cm} / \mathrm{s}$, in agreement with calculations by Horton et al. (1997b). The maximum simulated velocity is reached in November with speeds up to $50 \mathrm{~cm} / \mathrm{s}$. Onken and Sellschopp (2001) computed speeds of up to $60 \mathrm{~cm} / \mathrm{s}$ in October 1996 east of Cape Bon. The minimum of salinity is quite stable, ranging from 37.2 to $37.3 \mathrm{psu}$, and is located at the surface toward the African side, while the salinity increases from 37.3 psu to 37.5 psu toward the Sicilian side (Fig. 16a). During the summer months, the isohalines tend to progressively become closer to horizontal above $100 \mathrm{~m}$, with two sub-surface cores characterized by a minimum of salinity of about 37.3 psu. Both are located at about $40 \mathrm{~m}$ depth: the first is adjacent to the Tunisian side, while the second is more towards the center of the section (Fig. 16b). In spite of the reduced summer MAW volume transport, the monthly analyses of the salinity horizontal distribution in the Sicily Channel shows a higher lateral spreading during summer. This apparent contradiction appears to be related to the reduced impact of the wind stress on the MAW/LIW mixing with respect to winter (Manzella, 1994).

Beyond the Strait of Sicily, the simulated circulation reproduces the branching of the MAW into two main streams (Fig. 13). The southern branch follows the Tunisian shelf edge and eventually spreads over the wide shallow Libyan continental platform. The northern branch flows along the Sicilian shelf. Both have a strong seasonal variability, particularly in their volume transport and in their intrusion ca- pacity into the Sicilian Channel. The presence of these two MAW veins is well evidenced by the meridian section along $13^{\circ} \mathrm{E}$ (Fig. 15), from $35^{\circ} \mathrm{N}$ to $37.5^{\circ} \mathrm{N}$, in the form of separate subsurface cores with a salinity of $37.5 \mathrm{psu}$, situated at a depth of $50 \mathrm{~m}$. The southern branch, larger and less salty than the northern, has its maximum in autumn, while the northern branch is more evident in summer.

\subsubsection{The African shelf region}

The southern branch spreads over the north African shelf with a seasonal variability characterized by a decrease in the minimum of salinity from winter to summer, as a result of the lower degree of mixing of the MAW with the surrounding waters. The monthly distribution of the simulated salinity field increases from Cape Bon to the southeastern side of the domain, with a gradual modification of surface properties of the MAW. Strong anomalies of the temperature and salinity are found in the Gulf of Gabes, where steep horizontal temperature gradients practically persist throughout the year, and positive salinity gradients towards the coast occur mainly during the autumn/winter period. The extreme salinity values in the gulf increase in winter, passing from $37.6 \mathrm{psu}$ in August (Fig. 12b) to 38.4 psu in December-January (not shown). Such anomalies compare well with reality, as can be evidenced from AVHRR surface temperature maps (Le Vourch et al., 1992). During winter, a cold superficial coastal layer is established in the area, reaching a mean temperature of about $10.5^{\circ} \mathrm{C}$ (Fig. 17a). This low winter temperature is caused by the combined action of the strong negative surface heat fluxes and the shallow bathymetry. In summer the temperature reaches values over $30^{\circ} \mathrm{C}$ (Fig. 17c), due to the reversal of the surface heat fluxes with respect to winter.

The circulation in the rest of the northern African shelf is characterized mainly by a strong and relatively cooler eastward flow, which can be called the African MAW current, following closely the African shelf edge and making its way from the Sicily strait, past Lampedusa Island and subsequently steering southwards, coming close to the Libyan coast from $13^{\circ} \mathrm{E}$ onwards. This flow is particularly evident in the period May to December (Fig. 17d), developing into an intense stream during autumn, with flows reaching values of $20 \mathrm{~cm} / \mathrm{s}$. It is attenuated during winter when the circulation patterns are more complex. The dynamics of the area is also characterized by a permanent barotropic gyre located southeast of Cape Bon and by a pair of small-scale counter rotating gyres during summer, residing in the deeper waters off the Libyan coast between $14^{\circ} \mathrm{E}$ to $16^{\circ} \mathrm{E}$. This circulation results from the interaction of the African MAW with the warmer western perimeter of the Sidra gyre, and gives rise to the establishment of divergence zones and upwelling events in the proximity of the Libyan coast (Fig. 17d). Over the Libyan slope area in the southeastern part of the domain, the influence of the northward Sidra circulation bounded between longitudes $14^{\circ} \mathrm{E}$ to $16^{\circ} \mathrm{E}$ is replaced in the period December to April by an opposite general meandering consistent flow of MAW from the north (Fig. 17b). This flow car- 
(a)

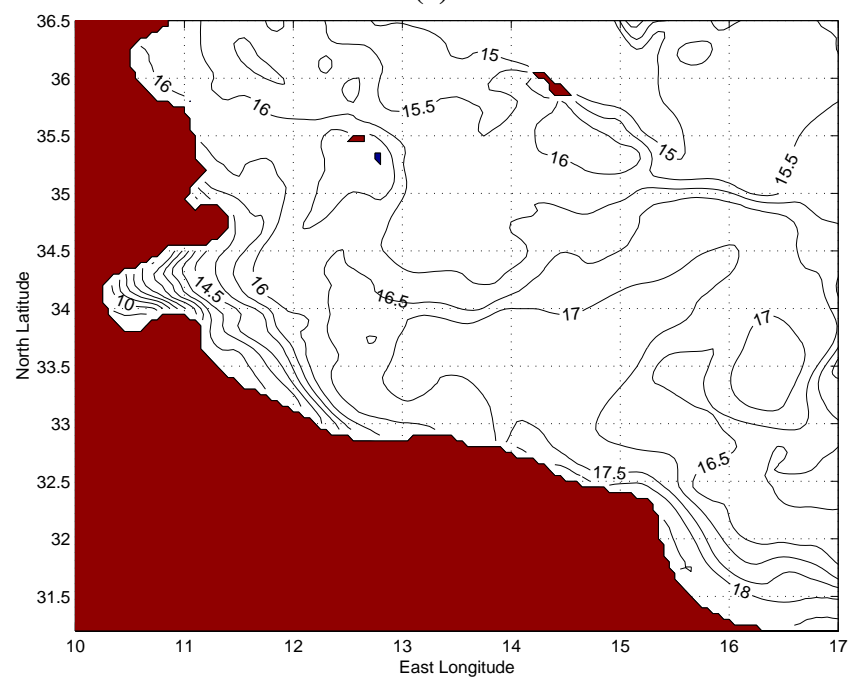

(c)

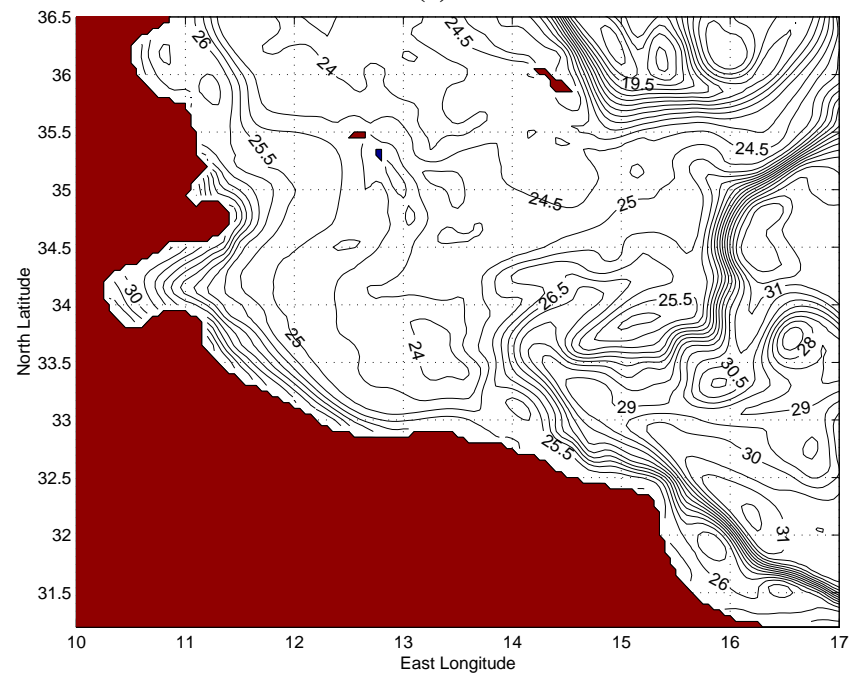

(b)

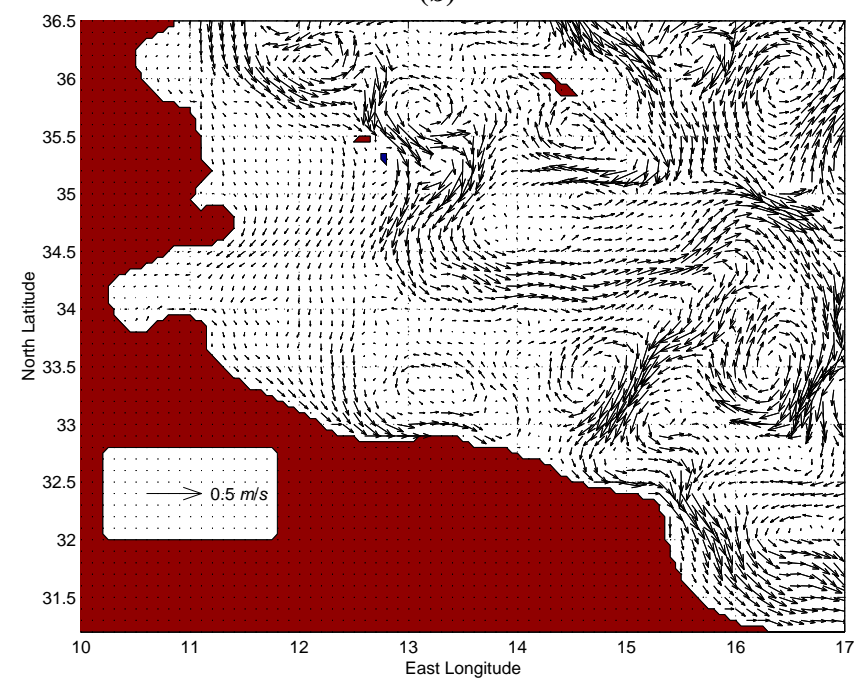

(d)

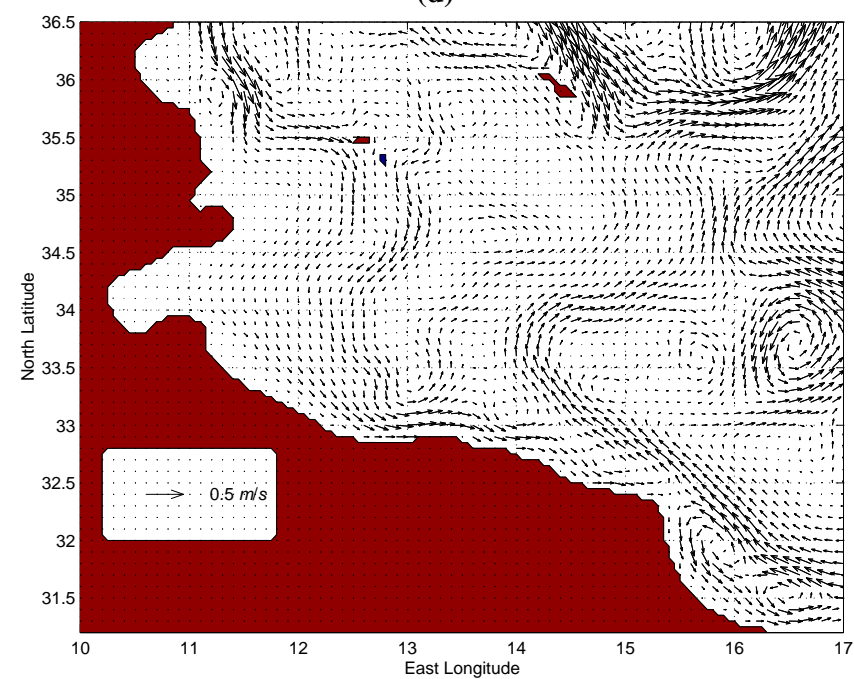

Fig. 17. Ten-day averaged temperature (a) and (c) and total velocity (b) and (d) horizontal fields at $5 \mathrm{~m}$ depth in February (a) and (b) and August (c) and (d). The temperature contour intervall is $0.5^{\circ} \mathrm{C}$. One vector every two grid points is plotted for velocity. Units are $\mathrm{m} / \mathrm{s}$.

ries with it an appreciable mesoscale component with eddy formations of opposite sign alongside to the flow. Unfortunately, no comparisons are possible with the bibliography or the climatology due to a lack of data in this area, as underlined by Barnkart and Brasseur (1998).

\subsubsection{The AIS circulation}

The northern branch of the MAW flow constitutes the energetic and meandering AIS moving eastward adjacent to the southern coast of Sicily where there is also a strong upwelling activity. Its simulated progression follows that proposed by Robinson et al. (1999), starting its path as a meander to the south of the Adventure Bank, proceeding southeastwards and looping back to the north around Malta, forming the Malta Channel Crest. In particular, during summer and autumn, the flow takes the consistency of a jet stream, gaining abruptly positive vorticity as it reaches the sharp shelf break to the east of Malta, and tending to deflect northward with an intense looping meander, forming the characteristic Ionian Shelf Break Vortex (Fig. 18b). The upshooting of the AIS follows closely the Ionian shelf break and subsequently extends as a relatively strong velocity front into the northwestern Ionian, where the circulation is predominantly anticyclonic at this time of the year, in agreement with Malanotte-Rizzoli et al. (1997). The contrast in temperature of the MAW exiting the Sicilian Channel with the warmer Ionian water produces a sharp temperature gradient (Fig. 11b) which is often evidenced over the Malta escarpment by conspicuous thermal features on the sea surface temperature AVHRR maps (Champagne-Philippe and Harang, 1982; Champagne-Philippe and Guevel, 1982). The model results also show the presence of mesoscale extensions and dynamic patterns associated with the instability of the AIS. The flow has a quasi-barotropic nature in the top layer, but is 
(a)

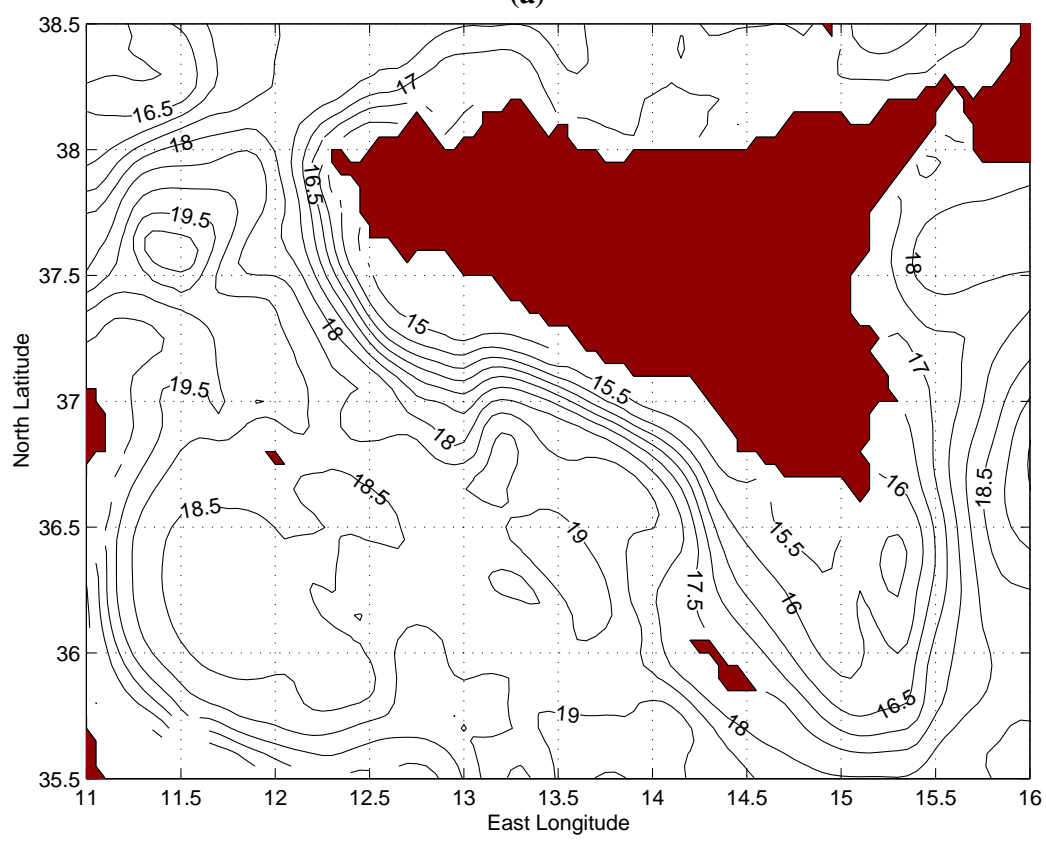

(b)

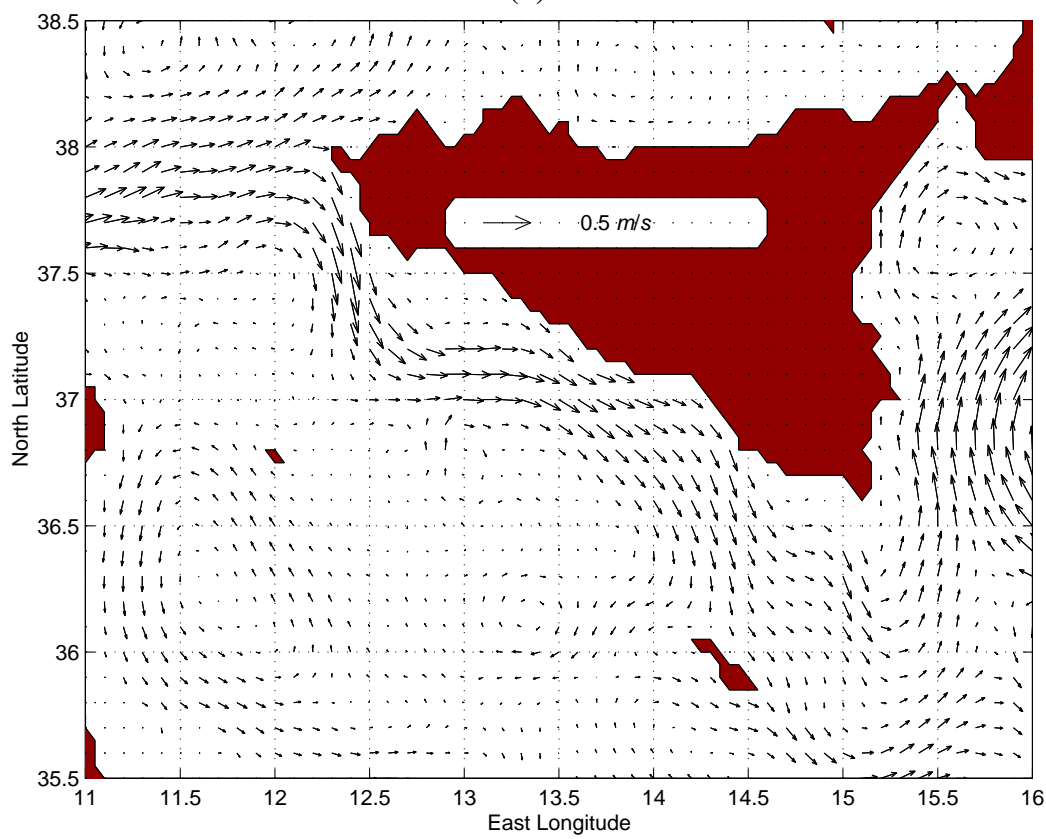

Fig. 18. Ten-day averaged (a) temperature and (b) total velocity fields at $30 \mathrm{~m}$ depth during September. The temperature contour interval is $0.5^{\circ} \mathrm{C}$. One vector every two grid points is plotted for velocity. Units are $\mathrm{m} / \mathrm{s}$.

accompanied by strong velocity shears in the bottom boundary layer and along its lateral boundaries as it extends horizontally down to a latitude of $36.4^{\circ} \mathrm{N}$, and vertically beyond the Sicilian shelf break.

The upwelling zone runs along the whole southern coast of Sicily and extends for a considerable distance (about $100 \mathrm{~km}$ ) offshore, especially over the Adventure Bank and on the Malta platform. This upwelling produces a large influence on the upper layer dynamics in the region and has important implications on the biological productivity and fisheries ac- tivity (Garcia Lafuente et al., 2002). The inclination of the isotherms (not shown) indicates that upwelling persists from May to December, being most evident in the summer months and early fall when the water column becomes well stratified and the thermocline is able to surface close to the southern Sicilian coast (Fig. 18a).

During winter, the AIS is less intense and the MAW flow tends to be more spread along the interior of the Sicilian Channel. There is a decrease in the amplitude of the intense looping meander in the upper Ionian Sea, and the exit 
(a)

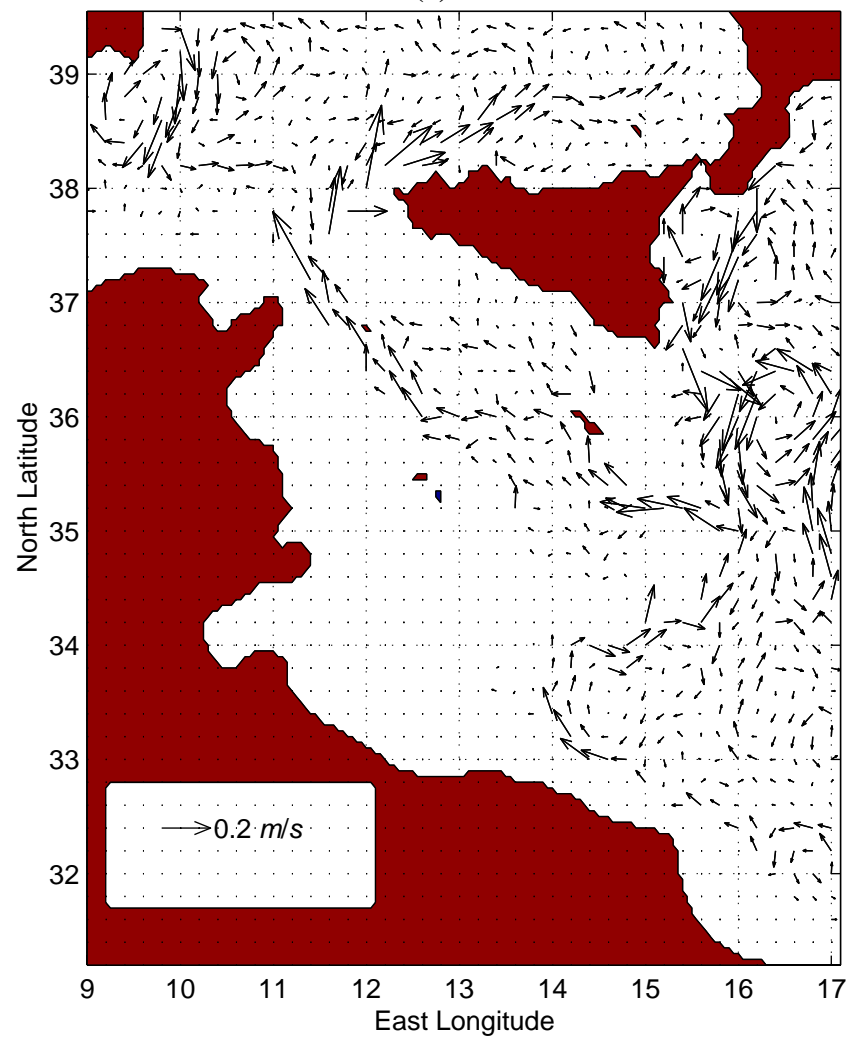

(b)

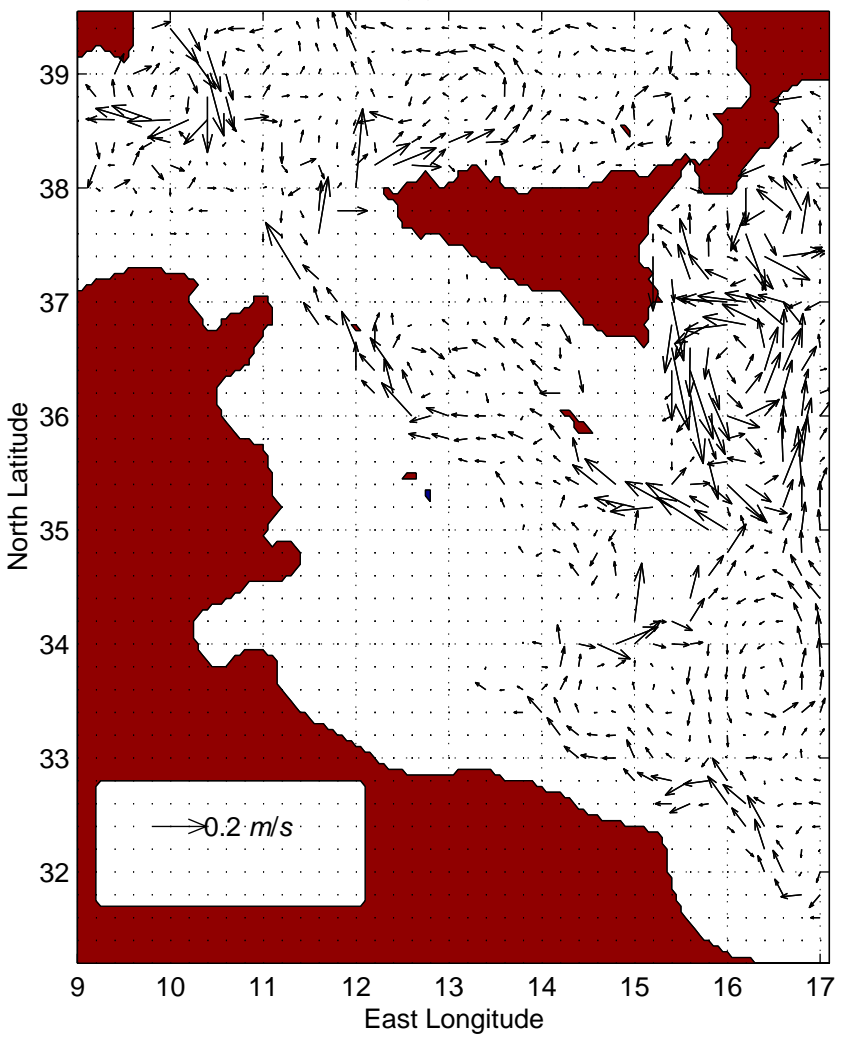

Fig. 19. The simulated 10-day averaged total velocity field at $280 \mathrm{~m}$ depth in (a) February and (b) August. One vector every four grid points is plotted. Units are $\mathrm{m} / \mathrm{s}$.

of the MAW is shifted further south where the shelf break slope is more tenuous, with the consequence that the fate of the MAW is more probable to branch southward and southeastward (Warn-Varnas et al., 1999), feeding the midMediterranean jet. Poulain (1998) reports that in winter, Langrangian drifters deployed upstream in the Sicilian Channel tended to avoid the Malta Channel route and proceeded south-southeastward to eventually reach the Ionian. In agreement with Horton et al. (1997a) and Robinson et al. (1999), the model results show that the northward veering of the MAW over the Malta Escarpment is also observed in spring and fall. This is in contradiction with earlier studies, such as Tziperman and Malanotte-Rizzoli (1991) and by Ovchinnikov (1966), who conclude that, on exiting the Channel, the MAW proceeds predominantly to the north during summer, and to the south and southeastward during the remainder of the year.

\subsection{The intermediate circulation}

The simulated circulation at $280 \mathrm{~m}$ (Fig. 19) replicates well the westward LIW flow. The variability of the LIW is limited mainly to the intensity of the flow rather than to its spatial location, in agreement with the diagnostic studies by Sorgente and Zavatarelli (2002). The vertical section at $13^{\circ} \mathrm{E}$ in
Fig. 15 shows the presence of the LIW in the Sicilian Channel with a typical salinity of more than 38.7 psu (in agreement with Grancini and Michelato (1987); Warn-Varnas et al. (1999); Sparnocchia et al. (1999)) at about $400 \mathrm{~m}$ depth. In the Channel the LIW stream is strongly controlled by the topography. It enters the area at about $15-16^{\circ} \mathrm{E}$, close to the Medina sill where the sea bottom rises from a depth of over $2000 \mathrm{~m}$ to a mean of around $400 \mathrm{~m}$. The morphology obliges the LIW to pass along the southern proximity of Malta and to subsequently spread again as it reaches the flanks of Adventure Bank. Before reaching the Strait of Sicily, the LIW follows a path through the Channel of Pantelleria, and subsequently proceeds through the wider Tunisian sill, reaching up to the bottom at $450 \mathrm{~m}$ depth. The isohalines below $200 \mathrm{~m}$ are generally unchanged, with an inclination toward the Tunisian coast throughout the year, as visible in Fig. 16. In this figure the LIW is visible below $300 \mathrm{~m}$ with a salinity maximum of 38.7 psu and well comparable with the observations by Sparnocchia et al. (1999) in the same area.

Beyond the Strait of Sicily, the entire LIW turns eastward due to the presence of the Skerki Bank and enters the Tyrrhenian Sea where the simulated speeds reach their highest values in winter. The same path for the LIW was observed by Sparnocchia et al. (1999) from CTD data gathered in November 1993. From the southern Tyrrhenian Sea one branch 
(a)

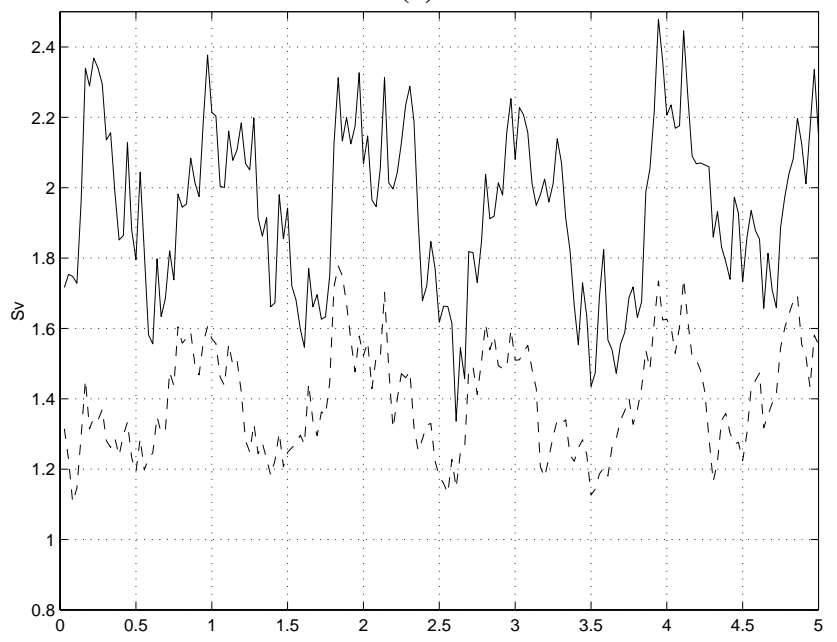

(b)

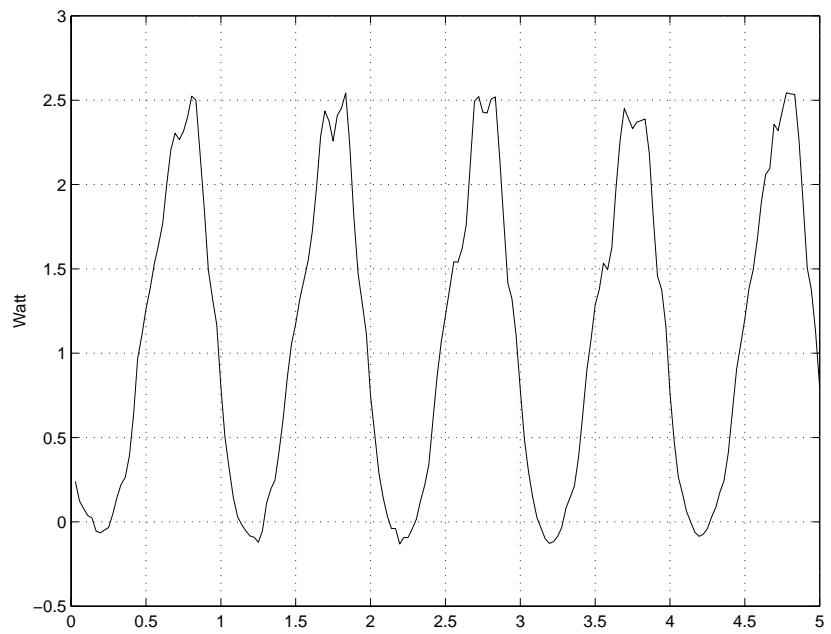

(c)

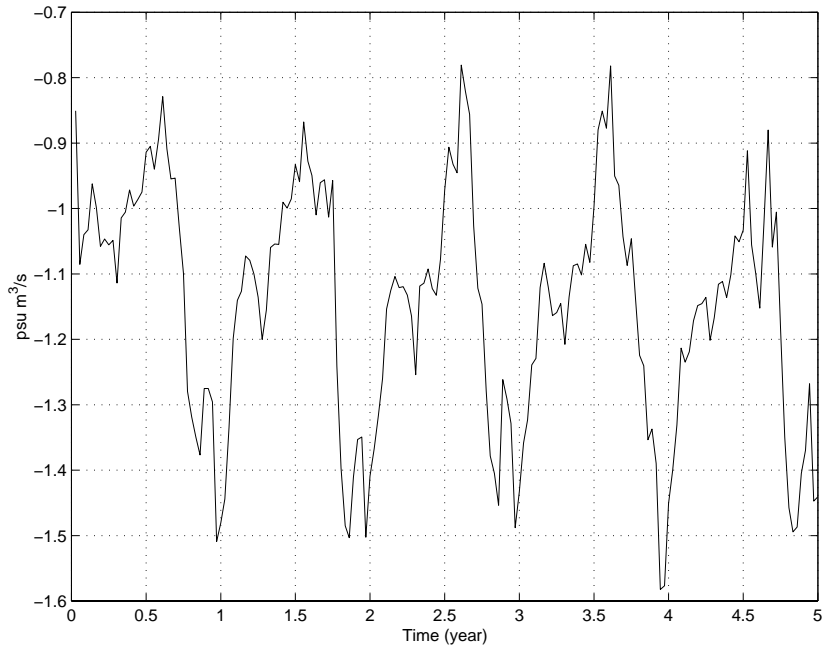

Fig. 20. The time series of mass, heat and salt transports at the Strait of Sicily for the 5 -year model integration. Positive values indicate an eastward transport. Panel a: Total and baroclinic (dashed line) volume transports. Units are Sverdrup $\left(10^{6} \mathrm{~m}^{3} / \mathrm{s}\right)$. Panel b: Net heat transport. Units are Watts $\times 10^{13}$. Panel c: Net salt transport. Units are $\mathrm{psu} \cdot \mathrm{m}^{3} / \mathrm{s} \times 10^{6}$.

appears to continue toward the Sardinia Channel following the Sardinian slope. This is well evidenced by the salinity sections across $9^{\circ} \mathrm{E}$ in February and August (Fig. 14), and agrees with what is reported by Hopkins (1988), who asserts that $1 / 2$ of the LIW enters the Tyrrhenian Sea recirculating out to the south, 1/4 crosses the Corsica Channel in the north, and $1 / 4$ is lost in mixing with the surrounding waters.

In the Sardinia Channel, at $9^{\circ} \mathrm{E}$, a layer with a maximum of salinity is visible at the intermediate depth. Its width and position varies seasonally. In February (Fig. 14a), there are two maxima of salinity at the intermediate depth in the Channel; the first is saltier and situated in the North, centered at about $700 \mathrm{~m}$; the second resides along the Tunisian coast at over $600 \mathrm{~m}$ with values of $38.57 \mathrm{psu}$, and with a simulated total velocity of about $5 \mathrm{~cm} / \mathrm{s}$. In August (Fig. 14b), there is only a deeper salinity maximum of 38.58 psu along Tunisia at about $700 \mathrm{~m}$ depth, and with a simulated total velocity of about $8 \mathrm{~cm} / \mathrm{s}$. This is not in agreement with Bouzinac et al. (1999), who found a maximum in excess of $38.68 \mathrm{psu}$ at $300-500 \mathrm{~m}$ in the middle of the Channel in November 1993, while Murru (personal communication) found a maximum at 38.67 psu at $500-600 \mathrm{~m}$ along Sardinia at $9^{\circ} \mathrm{E}$ during a cruise in the Sardinia Channel in May 2000.

\subsection{Transports at the Strait of Sicily}

A specific model result of direct interest is the volume transport across the Strait of Sicily into the Eastern Mediterranean basin. Time series of 10-day averaged simulated values of the total volume transport and of its baroclinic component (Fig. 20a) are used to make a quantitative study of the water exchange through the Strait. Such an analysis allows the detailed identification of the magnitude and seasonal variability of the transports. The annual mean of the total volume tranport computed during the last year of integration is about 
$1.9 \mathrm{~Sv}$; this is slightly higher than the $1.6 \mathrm{~Sv}$ computed from the coarse resolution model (Demirov and Pinardi, 2003). The transport estimates are higher in the period from November to May, with an average maximum of $2.2 \mathrm{~Sv}$, while the minimum occurs during summer from July to August, reaching below 1.6 Sv. The interannual variability during the "perpetual" simulation experiment shows a peak value of $2.4 \mathrm{~Sv}$ in December and a minimum of $1.4 \mathrm{~Sv}$ in July. The annual mean of the baroclinic component is $1.4 \mathrm{~Sv}$ and carries the greater share of the seasonal variability. The short-term variability of the transport values is also significant, with fluctuations of the order of $0.3-0.4 \mathrm{~Sv}$ being very common throughout the year. The seasonality is in good agreement with observations (Manzella, 1990; Grancini and Michelato, 1987; Astraldi et al., 1996) and with the OGCM model study of interannual variability (Pinardi et al., 1997); it is, however, in contrast with Moretti et al. (1993). From hydrographic measurements, Moretti et al. (1993) report a mean volume tranport under $1.0 \mathrm{~Sv}$ with an opposite seasonal pattern, that is a mean winter transport smaller than in summer. This apparent discrepancy has been explained by Pinardi et al. (1997) by observing that Moretti et al. (1993) considered only the baroclinic contribution to the transport across the Strait, and that this contribution was only $1 / 3$ of the total transport while the rest is due to the barotropic component. In our application the baroclinic component is found, however, to carry a higher proportion (about the 74\%) of the total volume transport.

The time series of the net heat transport (Fig. 20b) is fairly steady during the model integration, although a strong seasonal variability is also evident. The maximum of heat exchange is reached in September-October $\left(2.5 \times 10^{13}\right.$ Watts $)$, that is with a phase lag of four months with respect to the maximum in the total superficial heat flux over the model domain (Fig. 7b); the minimum is in March-April. The annual mean of $1.1 \times 10^{13}$ Watts, directed towards the eastern Mediterranean, is in agreement with Pinardi et al. (1997), who calculated $1.2 \times 10^{13}$ Watts, and the coarse resolution model results from Demirov and Pinardi (2003). The net salt transport (Fig. 20c) has an annual mean of about $1.2 \times 10^{6} \mathrm{psu} \mathrm{m}^{3} / \mathrm{s}$ toward the western basin, showing, also in this case, a strong seasonal variability, with a maximum in December-January and a minimum in July-August.

\section{Summary and Conclusions}

The Central Mediterranean region is characterized by a number of significant hydrodynamical processes and phenomena with strong variability at seasonal and shorter time scales. The general circulation is dictated mainly by the slow basin scale (vertical) thermohaline structure of the Mediterranean, in addition to important components related to meteorological forcing and the influence of the complex morphology. An eddy-resolving version of the free surface Princeton Ocean Model (POM) nested to the rigid lid MOM-OGCM (Modular Ocean Model - Ocean General Circulation Model) basin scale model is shown to correctly reproduce the seasonal climatological cycle of the circulation in the area, as evidenced by the comparison of the model results with the circulation patterns inferred from the bibliography and from remote sensed thermal AVHRR data. The five-year "perpetual" simulation experiment with climatological forcing contributes to give an improved description of the circulation, especially in its 3-D phenomenology, as well as to give a firsthand indication of important dynamical features pertaining to the Tunisian and Libyan near-shelf areas, where oceanographic knowledge is generally scarce due to lack of data.

The numerically efficient one-way off-line nesting technique used in this work is that adopted by the Mediterranean Forecasting System Pilot Project. It is shown to be adequate, even in the case of a complicated model domain characterized by strong exchange flows. The POM-MOM correlations show that the nested domain is able to generate high resolution information that is coherent with the nesting large scale.

The simulations have evidenced the presence of a strong, superficial mesoscale activity in the Sardinia Channel, particularly from November to March. Such activity is driven mainly by the inflow of MAW from the Algerian basin, calculated to be twice in winter than in summer. The eddies are generated by baroclinic instabilities from the meandering of the MAW stream and the variations in density with the surrounding superficial waters. The simulations show that these eddies are important in the transfer of the MAW into the Tyrrhenian Sea.

In the Sicilan Channel the model has underlined the presence of two main superficial MAW streams with a different seasonality in the mass transport. The southern flux moving along the north African coast is stronger in autumn, while the northern flow along the Atlantic Ionian Stream (AIS) increases in summer, meandering along the Sicilian shelf break, close to Malta. The model puts in evidence the seasonality of the northward veering of the AIS as it reaches the Ionian Sea. The pre-conditioning and pathways of the MAW towards the eastern Mediterranean are well described, together with the associated evolution of the mesoscale signals in the form of eddies, meanders and small-scale gyres. The simulated LIW flow can be followed in its progress along the Sicilian Channel, and shows seasonal differences in the mass transport, being greater in winter compared to summer.

The model is also used to quantify the volume transport across the Strait of Sicily. The flow is found to be predominantly baroclinic in nature (74\%), with a mean total transport of $1.9 \mathrm{~Sv}$ and a strong seasonal signal having a maximum spread over the winter months and a sharper minimum close to July.

Acknowledgements. This work has been partially funded by the EU MAST project MFSPP (Mediterranean Forecasting System Pilot Project, contract number MAS3-CT98-0171) and by the Italian national project SIMBIOS, Programma Operativo del Piano Ambiente Marino, Cluster C10, Progetto n. 13 (D.n. 778.RIC).

The authors thank Marco Zavatarelli from the University of Bologna for his precious suggestions and Filippo Angotzi for his essential technical support. 
Topical Editor N. Pinardi thanks a referee for his help in evaluating this paper.

\section{References}

Astraldi, M. and Gasparini, G. P.: The seasonal characteristics of the circulation inthe Tyrrhenian Sea, In: The seasonal and Interannual Variability of the Western Mediterranean Sea, (Ed) La Violette, P. E., Coastal and Estuarin Studies, Vol. 46. AGU, WA, 115-134, 1994.

Astraldi, M., Gasparini, G. P., Sparnocchia, S., Moretti, M., and Sansone, E.: The characteristics of the water masses and the water transport in the Sicily Strait at long time scalesthe eastern and western Mediterranean through the Strait of Sicily, Bulletin de l'Institut Oceanographique, Monaco, CIESM Science Series n 2, 95-115, 1996.

Astraldi, M., Balopoulos, S., Candela, J., Font, J., Gacic, M., Gasparini, G. P., Manca, B., and Theocharis, A.: The role of straits and channels in understanding the characteristics of Mediterranean circulation, Progress in Oceanography, 44, 65-108, 1999.

Barnkart, J. M. and Brasseur, P.: The general circulation in the Mediterranean Sea: a climatological approach, J. Marine Systems, 18, 41-70, 1998.

Bell, M. J.: Vortex stretching and bottom torque in the Bryan-Cox ocean circulation model, The Met. Office, Applications T.N. 17, 1997.

Bethoux, J. P.: Mean water fluxes across sections in the Mediterranean Sea, evaluated on the basis of water and salt budgets and of observed salinities, Oceanologica Acta, 3, 79-88, 1980.

Blumberg, A. F. and Mellor, G. L.: A description of a threedimensional coastal ocean circulation model Mediterranean Sea, In: Three-Dimensional Coastal Ocean Models, (Ed) Heaps, N. S., Am. Geophys. Union, 1-16, 1987.

Bouzinac, C., Font, J., and Millot, C.: Hidrology and currents observed in the channel of Sardinia during the PRIMO-1experiment from November 1993 to October 1994, J. Marine Systems, 20, 333-355, 1999.

Brasseur, P., Beckers, J. M., Brankart, J. M., and Schoenauen, R.: Seasonal temperature and salinity fields in the Mediterranean Sea: climatological analyses of a historical data set, Deep-Sea Res. I, 43, 159-192, 1996.

Champagne-Philippe, M. and Harang, L.: Surface Temperature fronts in the Mediterranean Sea from infrared satellite imagery, Hydrodynamics of semi-enclosed seas, J. C. J. Nihoul, 91-128, 1982.

Champagne-Philippe, M. and Guevel, D.: Etude du front de Malte, Ann. Hydrogr., 757, 65-87, 1982.

Demirov, E. and Pinardi, N.: The Mediterranean Sea variability 1999-2000: results from MFS analysis, Ann. Geophysicae, this issue, 2003.

Ezer, T. and Mellor, G. L.: Diagnostic and prognostic calculation of the North Atlanticcirculation and sea level using a sigma coordinated ocean model, J. Geophys. Res., 99, 14 159-14 171, 1994.

Fox, A. D. and Maskell, S. J.: A nested primitive equation model of the Iceland-Faeroe front, J. Geophys. Res., 101, 18 259-18 278, 1996.

Frassetto, R.: A study of the turbulent flow and character of the water massesover the Sicilian ridge in both summer and winter, Rapp. P. V. CIESM, 18, 3, 812-815, 1980.

Garcia Lafuente, J., Garcia, A., Mazzola, S., Quintanilla, L., Delgado, J., Cutitta, A., and Patti, B.: Hydrographic phenomena in- fluencing early life stages of the Sicilian Channel anchovy, Fisheries Oceanography, 11:1, 31-44, 2002.

Grancini, G. F. and Michelato, A.: Current structure and variability in the Strait of Sicily and adjacent area, Ann. Geophysicae, 5B 75-88, 1987.

Hopkins, T. S.: Physical processes in the Mediterranean basins, University of South Carolina Press., 269-310, 1978.

Hopkins, T. S.: Recent observations on the intermediate and deep watercirculation in the Southern Tyrrhenian Sea, Oceanologica Acta, n. SP, 41-50, 1988.

Horton, C., Clifford, M., and Schimtz, J.: Recent observations on the intermediate and deep water circulation in the Southern Tyrrhenian Sea, Oceanologica Acta, 5, 41-50, 1997a.

Horton, C., Clifford, M., Schimtz, J., and Kantha, L. H.: A real-timeoceanographic nowcast/forecast system for the Mediterranean Sea, J. Geoph. Res., 102, C11, 23 123-23 156, 1997 b.

Koch, S. E. and McQueen, J. T.: A survey of nested grid techniques and their potential for use within the MASS weather prediction model, NASA Technical Memorandum, 87 808, 25pp, 1987.

Korres, G. and Lascaratos, A.: An eddy-resolving model of the Aegean and Levantine basins for the Mediterranean Forecasting System Pilot Project (MFSPP): implementation and climatological runs, Ann. Geophysicae, this issue, 2003.

Krivosheya, V. G.: Water circulation and structure in the Tyrrhenian Sea, Oceanology, 23, 166-171, 1983.

Legates, D. R. and Wilmott, C. J.: Mean seasonal and spatial variability in gauge corrected global precipitation, Int. J. Climatol., 10, 111-127, 1990.

Le Vourch, J., Millot, C., Castagne, N., Le Borgne, P., and Olry, J.-P.: Atlas of Thermal Fronts of the Mediterranean Sea derived from Satellite Imagery, DMemoires de l'Institut oneanographique, 16, VI-152, 1992.

Lermusiaux, P. F. J.: Estimation and study of mesoscale variability in the Strait of Sicily, Dyn. Atmosph. Oceans, 29, 255-303, 1999.

Lermusiaux, P. F. J. and Robinson, A. R.: Features of dominant mesoscale variability, circulation patterns and dynamics in the Strait of Sicily, Deep-Sea Res. I, 48, 1953-1997, 2001.

Lozano, C. J., Haly, P. J., Arango, H. G., Sloan, Q., and Robinson, A. R.: Harvardcoastal/deep water primitive equation model, Harvard Open Ocean Model Reports, No. 52, Harvard Uni., Cambridge, MA, 1994.

Malanotte-Rizzoli, P. and Bergamasco, A.: The wind and thermally driven circulation of the eastern Mediterranean Sea, II, The baroclinic case, Dyn. Atmos. Oceans, 15, 355-371, 1991.

Malanotte-Rizzoli, P., Manca, B. B., Ribera D'Alcal, M., Theocharis, A., Bergamasco, A., Bregant, D., Budillon, G., Civitarese, G., Georgopoulos, D., Michelato, A., Sansone, E., Scarazzato, P., and Souvermezoglou, E.: A synthesis of the Ionian Sea hydrography, circulation and water mass pathways during POEM-Phase I, Prog. Oceanog., 39, 153-204, 1997.

Manzella, G. M. R.: The seasonal variability of the water masses and transport trough the Strait of Sicily, Coastal and Estuarin Studies, 46, 33-450, 1994.

Manzella, G. M. R., Gasparini, G. P., and Astraldi, M.: Water exchange between the eastern and western Mediterranean through the Strait of Sicily, Deep-Sea Res. I, 35, 1021-1035, 1988.

Manzella, G. M. R., Hopkins, T. S., Minnett, P. J., and Nacini, E. Atlantic Water in the Strait of Sicily,, J. Geophys. Res., 95, 15691575, 1990.

Mellor, G. L.: An equation of state for numerical models of oceans and estuaries, J. Atmos. Oceanic Tech., 8, 609-611, 1991. 
Mellor, G. L.: Users Guide for a Three Dimensional, Primitive Equation, Numerical Ocean Model, http://www.os.princeton.edu/WWWPUBLIC/htdocs.pom/, 40, 1998.

Mellor, G. L. and Yamada T.: Development of a turbulence closure model for geophysical fluid problems, Rev. Geophys. Space Phys., 20, 851-875, 1982.

Mellor, G. L., Ezer, T., and Oey, L. Y.: The pressure gradient conundrum of sigma coordinate ocean models, J. Atmos. Oceanic. Technol., 11, 1126-1134, 1994.

Moretti, M., Sansone, E., Spezie, G., and De Maio, A.: Results of investigations in the Sicily Channel (1986-1990), Deep-Sea Res. I, 40, 1181-1192, 1993.

Nittis, K. and Lascaratos, A.: Diagnostic and prognostic numerical studies of LIW formation, J. Marine. Sys., 18, 179-195, 1998.

Oey, 1.-Y.: Eddy energetics in the Faroe-Shetland channel: a modelresolution study, Cont. Shelf Res., 17, 1929-1944, 1998.

Oey 1.-Y. and Chen P.: A nested-grid ocean model: with application tothe simulation of meanders and eddies in the Norwegian Coastal Current, J. Geophys. Res., 97, $20063-20$ 086, 1992.

Onken, R. and Sellschopp, J.: Water masses and circulation between the eastern Algerian Basin and the Strait of Sicily in October 1996, Oceanologica Acta, 24, 151-166, 2001.

Ovchinnikov, I. M.: Circulation in the surface and intermediate layers of the Mediterranean, Oceanology, 6, 48-59, 1966.

Pinardi, N. and Navarra, A.: Baroclinic wind adjustement processes in the Mediterranean Sea, Deep Sea Res. II, 40, 1299-1326, 1993.

Pinardi, N., Korres, G., Lascaratos, A., Roussenov, V., and Stanev, E.: Numerical simulation of the interannual variability of the Mediterranean Sea upper ocean circulation, Geophys. Res. Letts., 24, 4, 425-428, 1997.

Pinardi, N., Antoine, D., Babin, M., Baretta, J., Bassini, S., Brenner, S., Crepon, M., Cruzado, A., Dandin, P., De May, P., Drago, A. F., Evensen, G., Gacic, M., Gasparini, G. P., Hamza, W., Lascaratos, A., Le Traon, P.-Y., Garcia, Lopez, M. A., Maillard, C., Manzella, G. M. R., Millot, C., Raicich, F., Raillard, O., Reid, P. C., Sorgente, R., Thanos, I., Triantafyllou, G., Tziavos, C., and Zodiatis, G.: The Mediterranean ocean forecasting system: the first phase of implementation, In: OCEANOBS 99 Conference, 1999.

Poulain, P. M.: Lagrangian measurements of the surface circulation in the Adriatic and Ionian Seas between November 1994 and March 1997, Rapp. Comm. Int. Mer Medit., 35, 190-191, 1998.
Robinson, A. R., Arango, H. G., Warn-Varnas, A., Leslie, W. G., Miller, A. J., Haley, P. J., and Lozano, C. J.: Real-time regional forecasting in modern approaches to data assimilation in ocean modeling, In: Malanotte-Rizzoli (gests Eds.), Elsevier, 1996.

Robinson, A. R., Sellschopp, J., Warn-Varnas, A., Anderson, L. A., and Lermusiaux, P. F. J.: The Atlantic Ionian Stream, J. Marine Systems, 20, 129-156, 1999.

Roussenov, V., Stanev, E., Artale, V., and Pinardi, N.: A seasonal modelof the Mediterranean Sea circulation, J. Geophys. Res., 100, 13 515-13 538, 1995.

Send, U., Font, J., Krahmann, G., Millot, C., Rhein, M., and Tintor, J.: Recent advances in observing the physical oceanography of the western Mediterranean Progress in Oceanography, 44, 37 64, 1999.

Sloam, N. Q.: Dynamics of Shelf/Slope Front: Process Studies and Data-Driven Simulations, PhD Thesis, Harvard Univ., Cambridge, MA, 1996.

Smagorinsky, J.: Some historical remarks on the use of nonlinear viscosities, In: Large eddy simulation of complex engineering and geophysical flows, (Eds) Galperin, B. and Orszag, S. A., Cambridge Univ. Press, 3-36, 1993.

Sorgente, R. and Zavatarelli, M.: Diagnostic simulations of the seasonalcirculation in the Sicily Channel, In: Proceedings of the "2nd International Conference on EuroGOOS", Rome 10 13 March 1999, in press, 2002.

Sparnocchia, S., Gasparini, G. P., Astraldi, A., Borghini, M., and Pistek, P.: Dynamics and mixing of the Eastern Mediterranean outflow in the Tyrrhenian Sea, J. Marine Systems, 20, 301-317, 1999.

Tziperman, E. and Malanotte-Rizzoli, P.: The climatological seasonal circulation of the Mediterranean Sea, J. Mar. Res., 49, 125,1991

Warn-Varnas, A., Sellschops, J., Haley, Jr., P. J., Leslie, W. G., and Lozano, C. J.: Strait of Sicily water masses, Dyn. Atmosph. Oceans, 29h, 437-469, 1999.

Wu, P. and Haines, K.: Modeling the dispersal of Levantine Intermediate Waterand its role in the Mediterranean deep water formation, J. Geophys. Res., 101, 3261-3271, 1996.

Zavatarelli, M. and Mellor, G. L.: A numerical study of the Mediterranean Sea circulation, J. Phys. Oceanogr., 25, 1384-1414, 1995.

Zavatarelli, M., Pinardi, N., Kourafalou, V. H., and Maggiore, A.: Diagnostic and prognosticmodel studies of the Adriatic Sea general circulation: Seasonal variability, J. Geophys. Res., 107, 120,2002 